Resolução de problemas via teoria de grafos 
SERVIÇO DE PÓS-GRADUAÇÃO DO ICMC-USP

Data de Depósito:

Assinatura:

\title{
Resolução de problemas via teoria de grafos
}

\author{
Renato Ferreira de Souza
}

Orientador: Prof. Dr. Sergio Henrique Monari Soares

Dissertação apresentada ao Instituto de Ciências Matemáticas e de Computação - ICMC-USP, como parte dos requisitos para obtenção do título de Mestre Programa de Mestrado Profissional em Matemática. VERSÃO REVISADA 
Ficha catalográfica elaborada pela Biblioteca Prof. Achille Bassi e Seção Técnica de Informática, ICMC/USP, com os dados fornecidos pelo(a) autor(a)

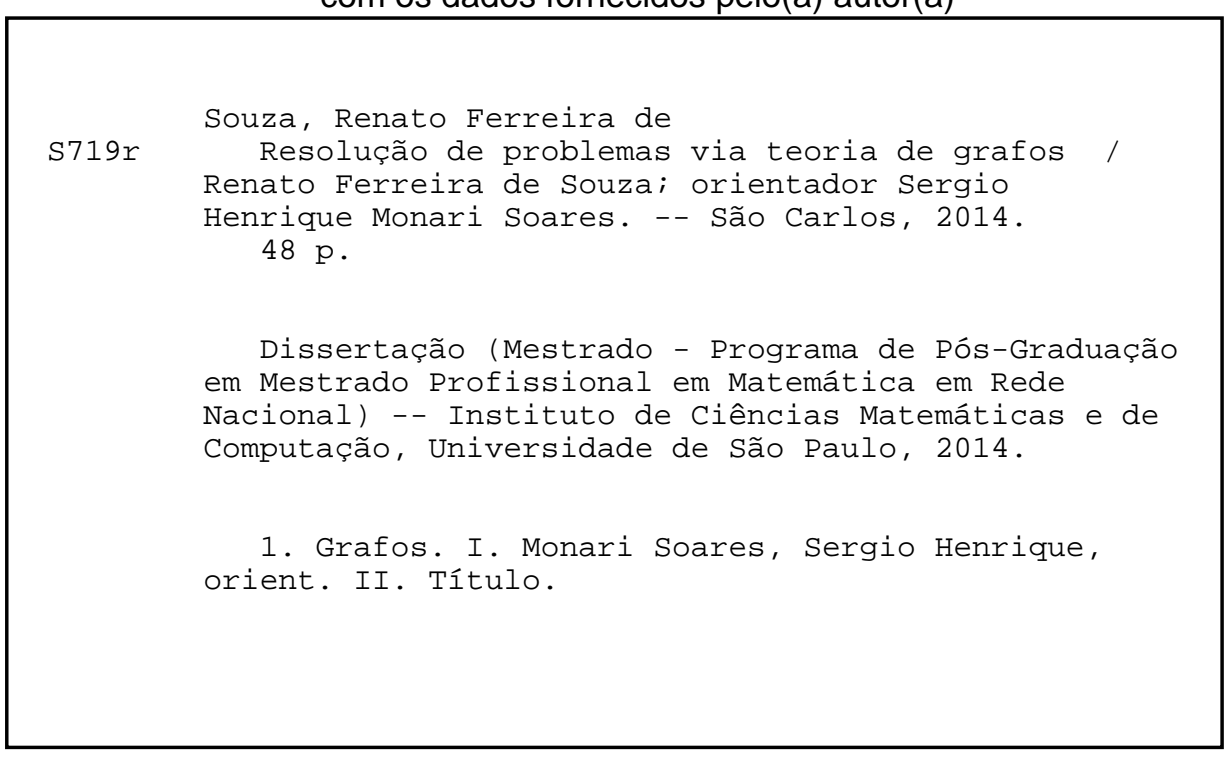


Dedico esse trabalho a minha esposa, Fernanda, que sempre me apoiou e incentivou a continuar os estudos. Minha paixão essa vitória não é somente minha e sim nossa. 



\section{Agradecimentos}

Agradeço em primeiro lugar a Deus que possibilitou que eu chegasse até aqui, iluminando cada passo deste árduo caminho, também a Nossa Senhora por sempre interceder por mim junto ao Pai, e colocando pessoas abençoadas em meu caminho.

À uma pessoa de enorme importância para que esta conquista tornasse possível, pessoa esta que no início do Profmat era minha noiva e hoje com a graça divina tornou-se minha esposa, e com o seu doce amor me incentivou a continuar.

Agradeço imensamente aos meus amados e insubstituíveis pais, e ao meu querido irmão Rodrigo que me acompanham desde o meu nascimento, comemorando comigo todas as vitórias e apoiando nos momentos de dificuldade.

Ao meu professor orientador, Sergio Henrique Monari Soares, pela grande disponibilidade de tempo em me atender principalmente aos sábados e pelo seu grande apoio com que conduziu esse trabalho, a ele meu eterno obrigado.

À toda turma 2012/2013 do Profmat, que foi se reduzindo com o passar dos tempos e desta forma selecionando guerreiros, e com o apoio da turma vencemos barreiras. O apoio de todos foi indispensável em minha caminhada. 

SOUZA, R. F. Resolução de problemas via teoria de grafos. 2014. 48 f. Dissertação (Mestrado) - Instituto de Ciências Matemáticas e de Computação, Universidade de São Paulo, São Carlos, 2014.

O objetivo deste trabalho é introduzir a noção de grafos familiarizando os alunos com um conceito pouco estudado no ensino fundamental e médio. Para isso, foram estudados algumas situações práticas e a resolução por meio de grafos. A apresentação da teoria de grafos é feita utilizando alguns dos problemas clássicos (Pontes de Königsberg e o Problema do caixeiro-viajante) que originaram a teoria tal como é conhecida nos dias de hoje.

Palavra-chave: Grafos. 



\section{Abstract}

SOUZA, R. F. Solving problems via graph theory. 2014. $48 \mathrm{f}$. Dissertação (Mestrado) - Instituto de Ciências Matemáticas e de Computação, Universidade de São Paulo, São Carlos, 2014.

The aim of this work is to introduce the notion of graphs familiarizing students with a little concept studied in elementary and middle schools. For this, some practical situations were studied and the resolution through graphs. The presentation of the theory of graphs is done using some of the classic problems (The Königsberg bridge problem and The travelling salesman problem) that originated the theory as it is known today.

Key word: Graphs. 



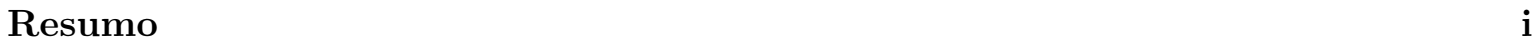

Abstract $\quad$ iii

$\begin{array}{ll}\text { Introdução } & 1\end{array}$

1 Grafos 3

1 Primeiras Noções . . . . . . . . . . . . . . . . . . . . 3

2 Tipos especiais de grafos . . . . . . . . . . . . . . . . . . 9

$2.1 \quad$ Grafos Eulerianos . . . . . . . . . . . . . . . . . . . . 12

2.2 Grafos Hamiltonianos . . . . . . . . . . . . . . . . . . . . . 15

2.3 Grafos valorados . . . . . . . . . . . . . . . . . 17

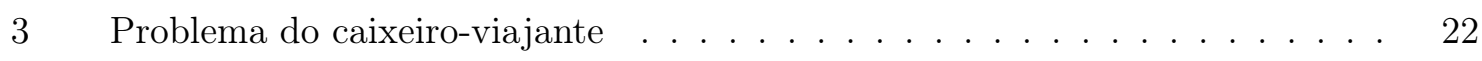

3.1 Métodos de solução para o PCV . . . . . . . . . . . . . . 22

2 Roteiro de aula $\quad 29$

$1 \quad$ Introdução . . . . . . . . . . . . . . . . . . . . . . . 29

1.1 Descrição da Comunidade Avaiense . . . . . . . . . . . . . . . . . . . . 29

1.2 Uma breve descrição da escola e dos alunos participantes . . . . . . . . 30

2 Organização da sala de aula . . . . . . . . . . . . . . . . . . . . 30

3 Folhas de Atividades . . . . . . . . . . . . . . . . . . . . . 31

4 Resultados . . . . . . . . . . . . . . . . . . . . 36

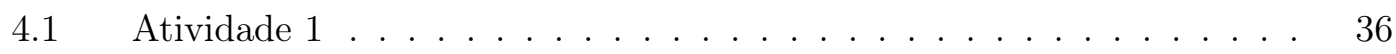

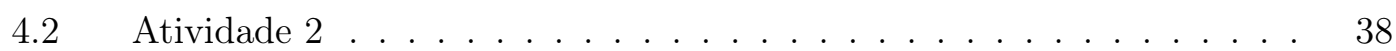

$5 \quad$ Resumo dos Resultados . . . . . . . . . . . . . . . . . . . . 41

5.1 Oitava série do ensino fundamental . . . . . . . . . . . . . . . . . 41

5.2 Terceira série do ensino médio . . . . . . . . . . . . . . . 42 
$6 \quad$ Considerações Finais . . . . . . . . . . . . . . . . . . . . . . . . . 42

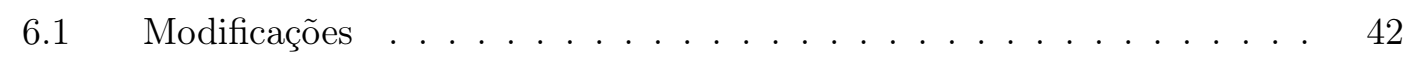

6.2 Conclusões finais . . . . . . . . . . . . . . . . . . . . . . . . . . . . . . . . . . . 43

6.3 Sugestões de Atividades . . . . . . . . . . . . . . . . . . 44

$\begin{array}{ll}\text { Referências Bibliográficas } & 47\end{array}$ 


\section{Introdução}

Objetivo deste trabalho é trazer o assunto de grafos para o cotidiano dos alunos do ensino médio, mesmo que de maneira simplificada. Apesar de se tratar de um conteúdo que não consta do currículo convencional de ensino, a abordagem proposta é acessível a esse nível e deste modo é possível introduzir diversos problemas interessantes que surgem em diversas áreas como no serviço de coleta de lixo, controle de tráfego, nas etapas de construção na engenharia civil, dentre tantas outras.

Em 1736, Leonhard Euler escreveu o primeiro artigo relacionado a grafos, de considerável importância não só para esta teoria, como também para a Matemática como um todo. Euler iniciou seus estudos em grafos discutindo um enigma, hoje conhecido como O Problema das Pontes de Königsberg, o qual ele resolveu e determinou um método geral para problemas do mesmo tipo. Posteriormente surgiram outros problemas que hoje são tidos como clássicos na teoria de grafos, a saber, o problema das quatro cores e o problema do caixeiro-viajante. Nos dias de hoje, os conceitos sobre grafos são usados nos ramos da Economia, Biologia, Computação, Engenharia, entre outros.

O presente trabalho está divídido em dois capítulos, sendo que o primeiro traz os conceitos de grafos que foram aqui utilizados na discussão de dois problemas clássicos: Pontes de Königsberg e o problema do caixeiro viajante. No segundo capítulo temos alguns exercícios sobre grafos que foram aplicados em sala de aula de uma escola pública e apresentamos os resultados obtidos. 



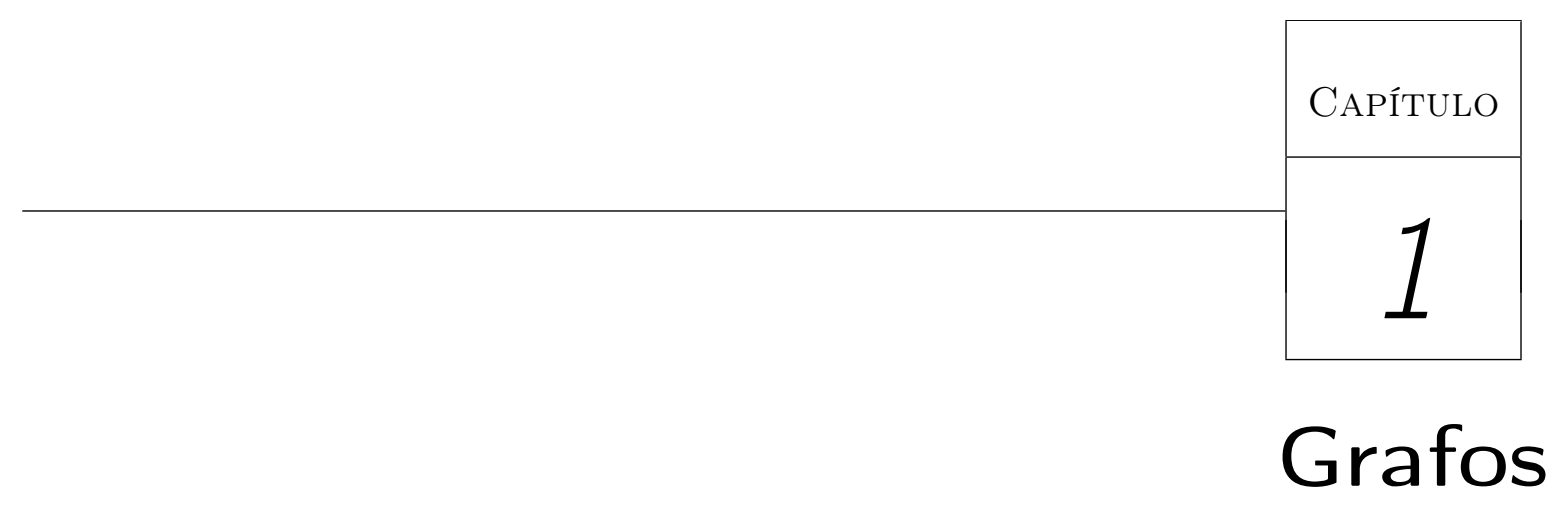

Neste capítulo apresentaremos conceitos básicos sobre a teoria dos grafos que serão utilizados nesta dissertação.

\section{Primeiras Noções}

Definição 1.1. Um grafo é um par $G=(V, A)$, onde $V$ é um conjunto finito não vazio e $A$ é uma família de pares não ordenados de elementos, não necessariamente distintos, de $V$.

Definição 1.2. Um grafo simples $G$ é um grafo $G=(V, A)$, onde $A$ é um conjunto de pares distintos não ordenados de elementos distintos de $V$.

Os elementos de $V$ são chamados de vértices do grafo, e os elementos $A$ são as arestas do grafo. Uma aresta $(a, b) \in A$ será denotada simplesmente por $a b$. Além disso, dizemos que uma aresta $a b$ contém os vértices $a$ e $b$, ou que $a$ e $b$ pertencem à aresta $a b$.

Definição 1.3. Dado um grafo $(V, A)$ e $a, b \in V$, dizemos que a é adjacente a $b$ se e somente $a b \in A$ e que aresta $a b$ é incidente aos vértices $a$ e $b . A$ notação $a \sim b$ significa que a é adjacente a $b$.

O número de vértices de uma grafo $(V, A)$ será representado por $|V|$ ou simplesmente $n$ e o número de arestas será representado por $|A|$ ou simplesmente $m$.

A Figura 1.2 é uma representação do grafo simples $(V, A)$, sendo $V=$ $\{a, b, c, d, e, f, g, h, i, j\}$ e $A=\{a b, a c, b d, c d, c g, c h, d e, d h, e i, f i, f j, g c, g h, h i\}$. 
No exemplo a seguir, vamos considerar um problema que pode ser abordado pela teoria de grafos.

Exemplo 1.4. Em uma pequena cidade do interior, Joana é uma agente de endemias que trabalha no combate à dengue, inspecionando residências e orientando os moradores sobre os possiveis focos da doença. Como faz todo o trajeto a pé, ela resolve buscar uma forma de otimizar o seu caminho, e para isso pede ajuda á sua amiga Isabela engenheira de tráfego. Primeiramente Isabela pede para a agente o mapa da região que será visitada e em seguida faz a identificação dessa região como um grafo.

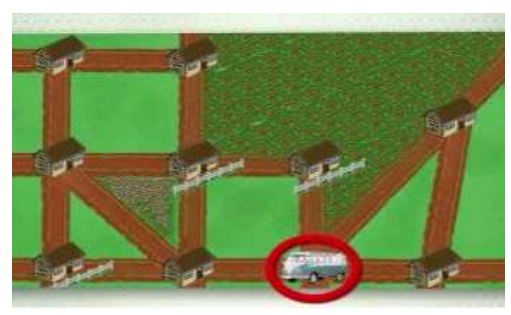

Figura 1.1: Representação (Fonte [1])

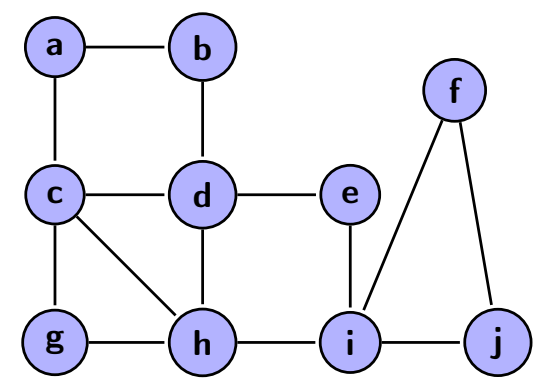

Figura 1.2: Representação em grafo

O que Joana deseja é percorrer um trajeto a partir de um ponto específico, passando por todas as casas, sem precisar repetir nenhuma rua, e voltar ao ponto de partida. A solução para o problema de Joana é o que será denominado de circuito de Euler, assunto que será abordado posteriormente.

Esse exemplo é uma versão do problema clássico das Sete Pontes de Königsberg. Königsberg foi uma cidade da antiga Prússia, que hoje faz parte da Rússia, chamada de Kaliningrado.

A Figura 1.3 mostra um mapa da cidade de Königsberg. A cidade é banhada pelo Rio Pregel que, ao atravessar a cidade se ramifica formando duas ilhas que estão ligadas entre si e ao restante da cidade por sete pontes. Segunda a lenda, os moradores da cidade gostavam de passear pela cidade à tarde e cogitaram se haveria um trajeto pela cidade em que cada ponte fosse atravessada exatamente uma vez e que voltasse para o ponto de partida. Como as suas tentativas foram sempre falhas, muitos deles acreditavam que não era possível encontrar tal 


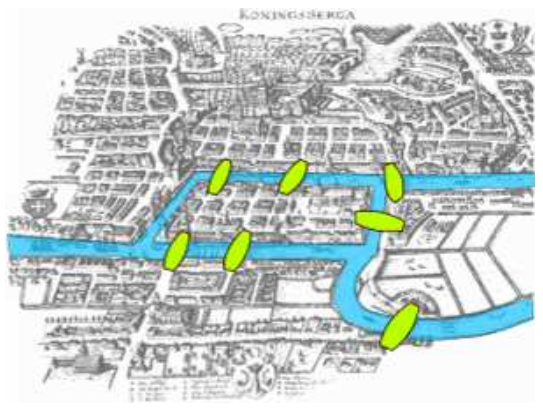

Figura 1.3: Mapa de Königsberg (Fonte [9])

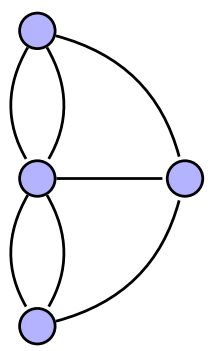

Figura 1.4: Representação em grafo

percurso, provocando muitas discussões para a época. Coube a Leonhard Euler ${ }^{1}$ a brilhante resolução por meio de uma representação alternativa do problema, usando pontos e segmentos

\footnotetext{
${ }^{1}$ Leonhard Euler (1707-1783), matemático e físico suíço. Ele não só fez contribuições decisivas e formativas para os temas de geometria, cálculo, mecânica e teoria dos números, mas também desenvolveu métodos para resolução de problemas em astronomia. Em 1727 mudou-se para São Petersburgo, onde ele se tornou associado da Academia de São Petersburgo de Ciências. Por meio de seus inúmeros livros e teses, Euler elevou o cálculo integral para um maior grau de perfeição, desenvolveu a teoria de funções trigonométricas e logarítmicas, reduziu as operações analíticas para uma maior simplicidade, e lançou uma nova luz sobre quase todas as partes da matemática pura. Em 1741, ele tornou-se membro da Academia de Berlim, onde por 25 anos produziu um fluxo constante de publicações. Em 1748, em sua obra Introduction in analysin infinitorum, ele desenvolveu o conceito de função e avançou o uso de infinitesimais e quantidades infinitas. Ele fez para a geometria analítica moderna e trigonometria o que os Elementos de Euclides tinham feito para a geometria antiga. Os seus livros de cálculo, Institutiones differentialis calculi, em 1755, e Institutiones Integralis, em 1768-70, serviram como protótipos para o presente, pois eles contêm fórmulas de diferenciação e numerosos métodos de integração, muitas das quais ele inventou para determinar o trabalho realizado por uma força e para a resolução de problemas geométricos, e fez avanços na teoria das equações diferenciais lineares, que são úteis na resolução de problemas em física. Euler retornou à Rússia em 1766 a convite de Catarina II. Logo após sua chegada em São Petersburgo, ele foi acometido por uma catarata e passou os últimos anos de sua vida em cegueira total. Apesar disso, a produtividade continuou intacta, sustentada por uma memória incomum e uma notável facilidade em cálculos mentais. Seus interesses eram amplos e seu trabalho apresentou uma exposição admiravelmente clara dos princípios básicos da mecânica, óptica, acústica e astronomia física. Euler dedicou considerável atenção ao desenvolvimento de uma teoria mais perfeita do movimento lunar, o que foi particularmente problemático, uma vez que envolveu as interações entre o Sol, a Lua e a Terra, conhecido atualmente como o problema dos três corpos e ainda sem solução. Ao longo de sua vida, Euler foi muito
} 
de retas, para elucidá-lo, de acordo com a Figura 1.4. Os vértices representam as regiões de terras, enquanto as arestas são as pontes. Notamos que para encontrar a solução de tal problema é necessário encontrar um caminho fechado contendo todas as arestas.

Definição 1.5. Sejam $G=(V, A)$ um grafo e $v \in V$ um vértice. O grau de $v$ é o número de arestas que incidem sobre ele e se denota por $d(v)$. Chama-se ordem do grafo $G$ ao número de vértices de $G,|V|$, que representa o cardinal de $V$.

Exemplo 1.6. Na Figura 1.2, temos $d(a)=2 ; d(b)=2 ; d(c)=4 ; d(d)=4 ; d(e)=2$; $d(f)=2 ; d(g)=2 ; d(h)=4 ; d(i)=4 ; d(j)=2$.

Definição 1.7. Um grafo direcionado (dígrafo) é um par ordenado $G=(V, A)$ onde existe uma relação de um vértice para outro, informando especificamente uma direção a ser tomada.

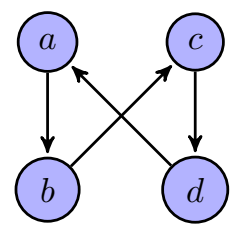

Figura 1.5: Grafo Direcionado

Observando a Figura 1.5, vemos que para ir do vértice $a$ para o $d$ será necessária uma passagem pelos vértices $b$ e $c$ uma vez que a aresta existente entre $a$ e $d$ incide em direção contrária.

No que segue, daremos mais algumas definições.

- Quando dois vértices estão ligados por mais de uma aresta, denomina-se multigrafo. Veja a Figura 1.6 para um exemplo.

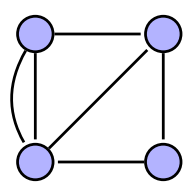

Figura 1.6: Multigrafo

- Uma aresta é um laço se para $v \in V, v v \in A$. Veja a Figura 1.7 para um exemplo.

- Duas arestas $a b$ e $c d \in A(G)$ são adjacentes se possuem um vértice em comum, isto é, se $a=c$ ou $a=d$, ou $b=c$ ou $b=d$.

- Sejam os grafos $G=\left(V_{G}, A_{G}\right)$ e $H=\left(V_{H}, A_{H}\right)$. Dizemos que $H$ é um subgrafo de $G$ se $V_{H} \subseteq V_{G}$ e $A_{H} \subseteq A_{G}$.

absorvido por problemas relacionados com a teoria dos números. Sua maior descoberta, em 1783, foi a lei da reciprocidade quadrática, que se tornou uma parte essencial da teoria dos números moderna. 


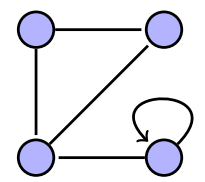

Figura 1.7: Grafo com Laço

Exemplo 1.8. Sejam $G$ e $H$ os seguintes grafos:

$$
\begin{array}{ll}
V(G)=\{1,2,3,4\} & V(H)=\{1,3,4\} \\
A(G)=\{\{1,2\},\{1,3\},\{2,3\},\{2,4\},\{3,4\}\} & A(H)=\{\{1,3\},\{3,4\}\}
\end{array}
$$

Note que $V(H) \subset V(G)$ e $A(H) \subset A(G)$ e, assim, $H$ é um subgrafo de $G$. Graficamente, esses grafos se apresentam como segue

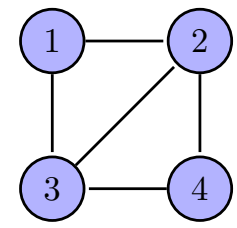

Figura 1.8: Grafo G

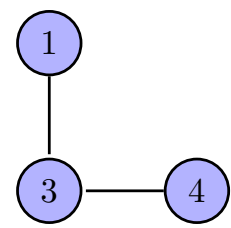

Figura 1.9: Grafo $H$

Teorema 1.9. Seja $G=(V, A)$ um grafo não orientado e com $m$ arestas, então:

$$
\sum_{v \in V} d(v)=2|A|
$$

Isto é, "a soma dos graus dos vértices de um grafo é sempre o dobro do número de arestas".

Demonstração. Considerando que cada uma das arestas apresentam dois vértices, e com isso contando a quantidade de arestas por vértice, teremos que toda aresta será contada duas vezes, deste modo, a soma dos graus dos vértices será o dobro da quantidade de arestas.

Observação 1.1. Para a validade do Teorema 1.9, a aresta em um laço deve ser contada duas vezes.

Exemplo 1.10. Dez amigos se encontram após longo tempo separados. Quando se encontram ocorre uma grande troca de aperto de mãos. Observando que cada um dos dez amigos 


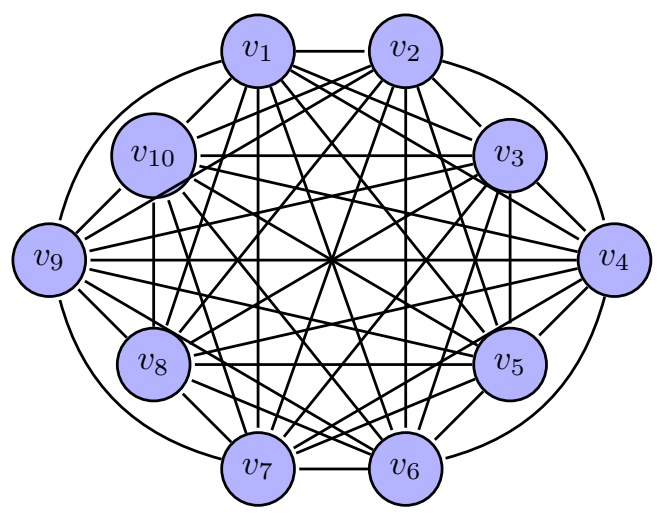

Figura 1.10: Representação do grafo associado ao problema

comprimentariam os nove outros amigos pode-se concluir que ocorreram quantos apertos de mãos?

Associando o problema para grafos, os amigos são os vértices $V$ e os apertos de mãos como as arestas $A$. $O$ grau dos vértices é $d\left(v_{i}\right)=9$ com $i \in\{1,2, \ldots, 10\}$, portanto a soma de todos os graus será, 10.9=90. Porém, sabemos que a ligação $v_{1}$ com $v_{2}$ é a mesma de $v_{2}$ com $v_{1}$, e desta forma o número de arestas do grafo é dado por $|A|=45$.

Como corolário deste teorema temos:

Corolário 1.11. Em todo grafo o número de vértices de grau ímpar é par.

Demonstração. Suponhamos que um grafo tenha um número ímpar de vértices de grau ímpar. Desse modo, a soma desses graus seria ímpar. Por outro lado, a soma dos graus do vértices de grau par é sempre par. Sendo assim, a soma dos graus dos vértices desse grafo seria ímpar, contradizendo o Teorema 1.9.

Valendo-se do conceito de Matrizes que é estudado tradicionalmente no segundo ano do ensino médio, podemos fazer uma outra demonstração do Teorema 1.9. Para fazer isso vamos primeiramente representar grafos de por meio de matrizes.

Dado um grafo $G=(V, A)$, com $n$ vértices representados por $1,2, \ldots, n$, seja $M=\left[m_{i j}\right]$ a matriz $n \times n$ dada por

$$
m_{i j}= \begin{cases}1 & \text { se } i \text { é adjacente a } j \\ 0 & \text { caso contrario. }\end{cases}
$$

Essa matriz denomina-se matriz de adjacência do grafo $G=(V, A)$. Por exemplo, o grafo da figura 1.11, possui matriz de adajacência dada por

$$
M=\left[\begin{array}{lllll}
0 & 1 & 1 & 0 & 0 \\
1 & 0 & 1 & 1 & 0 \\
1 & 1 & 0 & 0 & 1 \\
0 & 1 & 0 & 0 & 1 \\
0 & 0 & 1 & 1 & 0
\end{array}\right]
$$




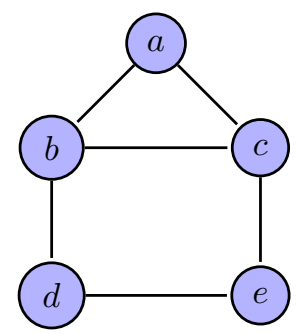

Figura 1.11: Grafo simples

A técnica para provar o Teorema 1.9 é então contar quantos 1s há nesta matriz. De fato, note que para para cada aresta de $G$ há exatamente dois 1 na matriz (se $v_{i} v_{j} \in A$, então há um 1 na posição $i j$ e um 1 na posição $j i$ ). Assim, o número de 1 na matriz é exatamente $2 m$, onde $m$ é o número arestas.

\section{Exercício 1.12.}

1. Um determinado reinado tem 100 cidades e saem quatro estradas de cada uma delas. Quantas estradas existem ao todo neste reinado?

2. Uma turma tem 30 alunos. É possivel que nove deles tenham 3 amigos cada (na turma), onze tenham 4 amigos e dez tenham 5 amigos?

3. Mostre que em todo grupo de pessoas, existem pelo menos duas que possuem o mesmo número de conhecidos no grupo.

4. Observando a representação em grafo da Figura 1.2, construa a sua matriz de adjacência.

5. Considerando a matriz de adjacência abaixo, faça sua representação em Grafo.

$$
X=\left[\begin{array}{llllllll}
0 & 1 & 1 & 0 & 0 & 0 & 0 & 0 \\
1 & 0 & 0 & 1 & 0 & 0 & 0 & 0 \\
1 & 0 & 0 & 1 & 0 & 0 & 0 & 0 \\
0 & 1 & 1 & 0 & 0 & 0 & 0 & 0 \\
0 & 0 & 0 & 0 & 0 & 1 & 0 & 0 \\
0 & 0 & 0 & 0 & 1 & 0 & 1 & 0 \\
0 & 0 & 0 & 0 & 0 & 1 & 0 & 1 \\
0 & 0 & 0 & 0 & 0 & 0 & 1 & 0
\end{array}\right]
$$

\section{Tipos especiais de grafos}

Definição 1.13. Um grafo é dito completo quando todos os pares de vértices distintos são adjacentes. Um grafo completo com $n$ vértices se denota por $K_{n}$. 


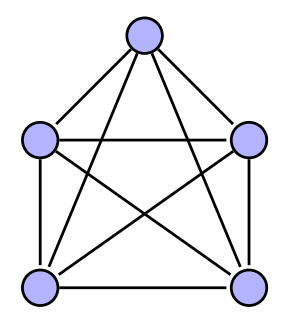

Figura 1.12: Representação de um grafo completo $K_{5}$

A Figura 1.12 é a representação de um grafo completo $K_{5}$. Outro exemplo de um grafo completo é a situação apresentada na Figura 1.10.

Para a determinação do número de arestas de um grafo completo deve-se realizar a combinação dos vértices. Por exemplo

$$
\left|A\left(k_{6}\right)\right|=\left(\begin{array}{l}
6 \\
2
\end{array}\right)=15, \quad\left|A\left(k_{n}\right)\right|=\left(\begin{array}{l}
n \\
2
\end{array}\right)=\frac{n !}{(n-2) ! \cdot 2 !} .
$$

Definição 1.14. Seja $G$ um grafo. Um grafo $\bar{G}$ é complementar de $G$ sempre que $V(G)=$ $V(\bar{G})$ e $A(\bar{G})=\{a b: a, b \in V(G), a \neq b, a b \notin A(G)\}$.
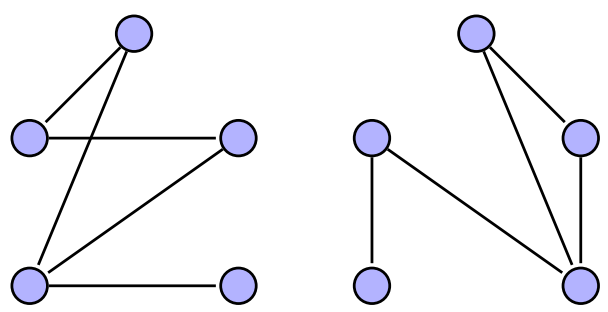

Figura 1.13: Representação de grafos complementares

Definição 1.15. Um grafo $G$ é nulo se $A(G)=\emptyset$. Isto é, um grafo sem arestas.

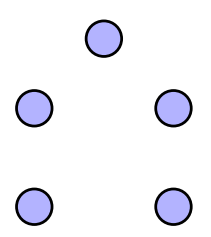

Figura 1.14: Grafo nulo

Definição 1.16. Se todos os vértices de um grafo $G$ têm o mesmo grau $k$, dizemos que $G$ é regular de grau $k$, ou ainda $k$-regular.

Observamos que todo grafo completo é regular, mas nem todo regular é completo. ]

Definição 1.17. Seja $G=(V, A)$ um grafo. Um passeio em $G$ é uma sequência (ou lista) finita de arestas $P=\left(v_{0} v_{1}, v_{1} v_{2}, \ldots, v_{l-1} v_{l}\right)$. O número $l$ denomina-se o comprimento desse 


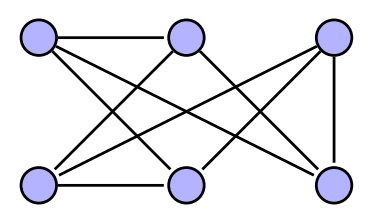

Figura 1.15: Representação de um grafo 3-regular

passeio. Quando todas as arestas do passeio são distintas, o passeio é chamado de trilha; se $v_{0}=v_{l}$ o passeio denomina-se trilha fechada, caso contrário denomina-se trilha aberta.

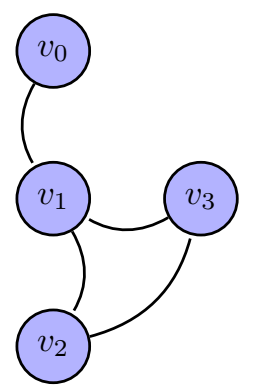

Figura 1.16: Passeio

Definição 1.18. Um caminho em um grafo $G$ é um passeio em $G$ em que nenhum vértice é repetido, a menos dos extremos.

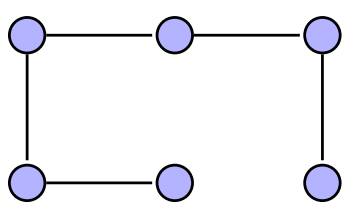

Figura 1.17: Exemplo de caminho

Definição 1.19. Sejam $G$ e $a, b \in V(G)$. Dizemos que a é ligado a $b$ se existe um caminho cujo primeiro vértice é a e o último é b.

Definição 1.20. Um grafo é chamado conexo se cada par de vértices no grafo está ligado por um caminho.

Definição 1.21. Um ciclo é um grafo regular conexo de grau 2.

Observamos que um caminho é um ciclo do qual foi retirada uma aresta.

Exemplo 1.22. Em um país existem 15 cidades, cada uma das quais está ligada por uma estrada a pelo menos 7 outras. Prove que o grafo das estradas desse país é conexo, ou seja, prove que é possivel ir de qualquer cidade à uma outra qualquer, possivelmente passando por algumas cidades intermediárias. 


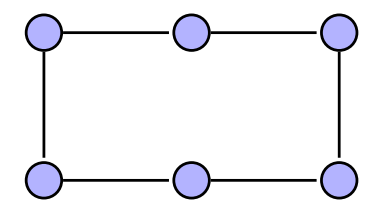

Figura 1.18: Ciclo

Vamos considerar duas cidades quaisquer e supor que não existe tal caminho ligando as duas. Sendo assim, não existe uma sequência de estradas, com o final de cada uma delas coincidindo com o início da próxima, ligando as duas cidades. Sabe-se que cada uma dessas duas cidades está ligada a pelo menos outras 7 estradas. Estas 14 estradas têm que ser todas distintas: se duas delas fossem a mesma, existiria um caminho que ligaria as duas cidades dadas inicialmente (veja a Figura 1.19). Portanto, temos que este país tem pelo menos 16 cidades diferentes, o que contradiz a enunciado do problema.

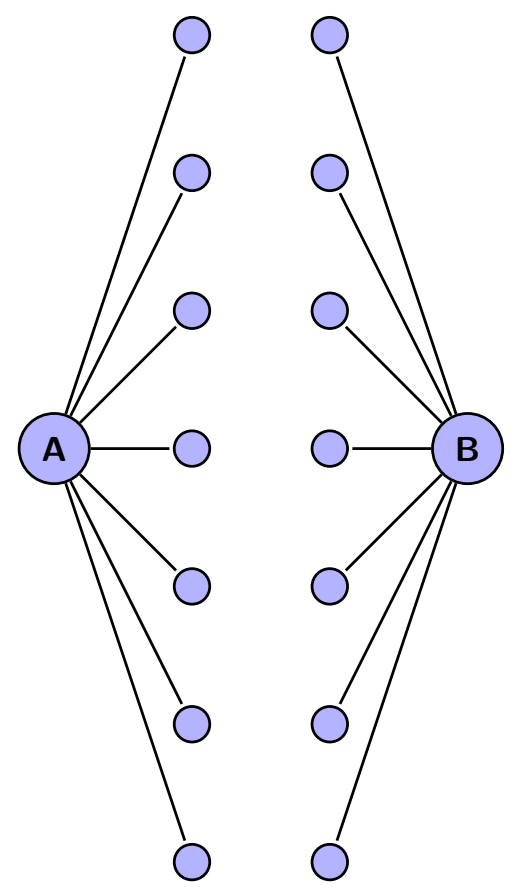

Figura 1.19

\subsection{Grafos Eulerianos}

Motivados pelo problema das Sete Pontes de Königsberg, somos levados à seguinte definição:

Definição 1.23. Seja $G=(V, A)$ um grafo. Um passeio em $G$ que percorre cada aresta de $G$ exatamente uma vez é chamado caminho de Euler. Um caminho de Euler que se inicia e termina no mesmo vértice é chamado circuito de Euler. Por fim, se G possui um circuito de Euler, dizemos que $G$ é um grafo euleriano. Se o grafo não possui um circuito de Euler, mas sim um caminho de Euler, ele será denominado semieuleriano. 

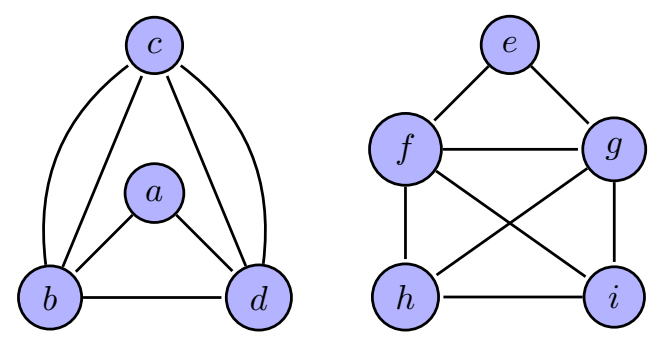

Nas figuras acima, temos dois exemplos, o primeiro de um grafo euleriano e o segundo de um grafo semieuleriano. Para primeira figura encontramos uma trilha fechada (ab,bc,cb,bd,dc,cd,da). Para a segunda figura encontramos uma trilha aberta (hg,gf,fi,ih,hf,fe,eg,gi).

No que segue, vamos estabelecer uma condição necessária para um grafo ser euleriano. Iniciamos com o seguinte lema.

Lema 1.24. Se todo vértice de um grafo $G$, não necessariamente simples, possui grau maior ou igual a 2, então $G$ contém um ciclo.

Demonstração. Se $G$ contém laços ou arestas múltiplas, o resultado é imediato. Suponhamos que $G$ seja um grafo simples. A partir de um vértice $v_{i}$ qualquer iniciamos a trilha partindo para um $v_{i+1}$ adjacente e diferente de $v_{i-1}$ qualquer, vértices estes garantidos pela hipótese, como $G$ possui um número finito de vértice em algum momento deste procedimento escolheremos um vértice já escolhido antes, e assim produzindo um ciclo.

Teorema 1.25. Um grafo conexo Gé euleriano se, e somente se, todos os seus vértice apresentarem grau par.

Demonstração. Suponhamos que $G$ seja euleriano; assim, todos os vértices possuem grau par. De fato, como $G$ possui uma trilha fechada, então devemos começar e terminar em um mesmo vértice, desta forma cada vez que se chega em um vértice necessita de uma nova aresta para sair dele. Logo, o grau de cada vértice necessariamente é par. Reciprocamente, suponhamos que todos os vértices têm grau par. Argumentaremos por indução no número de arestas $m$. Por vacuidade o teorema é válido quando $m=0$. Suponhamos que o teorema seja válido para todos os grafos com menos de $m$ arestas. Sendo $G$ conexo, todos os vértices apresenta grau maior que 2, pois sabemos que os graus são pares. Pelo Lema 1.24, temos um ciclo. Dentre todas as trilhas fechadas, escolhemos uma trilha $T$ de comprimento máximo. Se $T$ tiver comprimento $m$, o teorema estaria demonstrado. Caso contrário, considere a trilha $H$ obtida pela retirada de uma das arestas de $T$. Como foi retirado um número par de arestas de cada vértice de $T$ e, pela hipótese, todos os vértices apresentam o grau do vértice pares, ao menos uma das componentes de $H$ tem vértice comum com o $T$ e tem todos os graus pares. Pela hipótese de indução, $H$ tem uma trilha fechada que passa por todos os vértices de $H$, e podemos formar uma trilha fechada maior conectando $T$ com a trilha em $H$, mas isto contrariaria a maximalidade na escolha de $T$ e o demonstração do teorema está concluída. 
Voltando ao problema das Sete Pontes de Königsberg, vemos pelo Teorema 1.25 que é impossível atravessar todas as pontes e retornar ao ponto de partida sem passar mais de uma vez por todas elas, porque, o grafo que representa as pontes tem vértices de grau ímpar. No entanto, persiste a questão da existência de um trajeto pela cidade atravessando todas as pontes sem passar mais de uma vez por uma delas sem a necessidade de retornar ao ponto de partida, ou seja, a questão da existência de um caminho de Euler. A resposta é dada pelo próximo resultado.

Corolário 1.26. Um grafo conexo (não necessariamente simples) G é semieuleriano se, e somente se, houver um único par de vértices de grau ímpar.

Demonstração. A ideia é acrescentar uma aresta a dois vértices de grau ímpar e usar o teorema anterior.

\section{Exercício 1.27.}

1. O Caso Count Van Diamond. A planta abaixo é da residência do bilionário Count Van Diamond, que acaba de ser assassinado. Sherlock Gomes (um conhecido detetive que nas horas vagas é um estudioso da teoria de grafos) foi chamado para investigar o caso. O mordomo alega ter visto o jardineiro entrar na sala da piscina (lugar onde ocorreu o assassinato) e logo em seguida sair daquela sala pela mesma porta que havia entrado. O jardineiro, contudo, afirma que ele não poderia ser a pessoa vista pelo mordomo, pois ele havia entrado na casa, passado por todas as portas uma única vez e, em seguida, deixado a casa. Sherlock Gomes avaliou a planta da residência (conforme figura abaixo) e em poucos minutos declarou solucionado o caso. Quem poderia ser o suspeito indicado por Sherlock Gomes? Qual o raciocínio utilizado pelo detetive para apontar o suspeito?

(Fonte: [10])

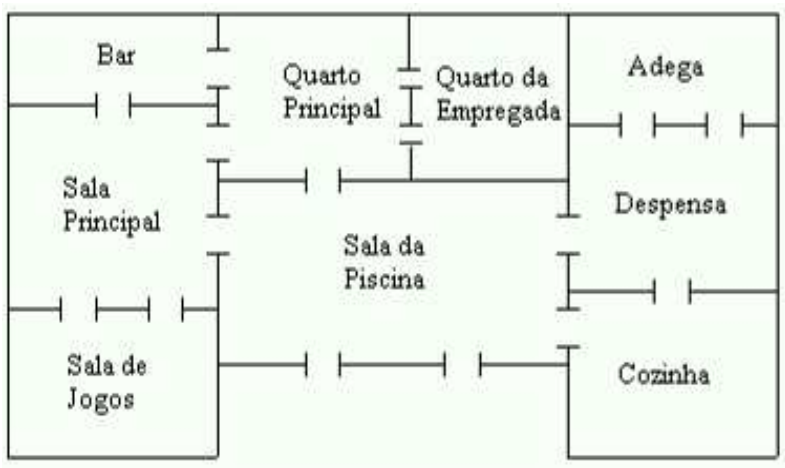

Figura 1.20: (Fonte: [10]) 
2. Um grupo de ilhas estão ligados por pontes de modo que é possivel andar de uma itha para outra qualquer. Um turista percorreu todas as ilhas cruzando cada ponte exatamente uma vez, tendo visitado a ilha de Tripla três vezes. Quantas pontes há em Tripla se:

(a) o turista não começou e nem terminou o seu percurso na ilha de Tripla;

(b) o turista começou o seu percurso em Tripla, mas não termnou por lá;

(c) o turista começou e terminou o seu percurso na ilha de Tripla;

3. (a) Uma peça de fio tem $120 \mathrm{~cm}$ de comprimento. É possivel usá-la para formar arestas de um cubo com arestas de $10 \mathrm{~cm}$ ?

(b) Qual o menor números de cortes que é preciso fazer no fio para que se possa formar o cubo desejado?

\subsection{Grafos Hamiltonianos}

Para motivar a próxima definição, vamos considerar The Icosian game, o qual é um jogo inventado em 1857 por William Hamilton. ${ }^{2}$ O jogo envolvia um dodecaedro onde cada um dos seus 20 vértices receberam nomes de cidades importantes na época: Dublin, Roma, Paris, Madrid, etc. O objetivo do jogo era que o jogador viajasse "ao redor do mundo", obtendo uma viagem circular, num itinerário contínuo pelas arestas de um dodecaedro, que saindo de uma determinada cidade, incluísse todas as cidades exatamente uma vez. Observa-se que a única restrição neste processo era que só era possível viajar de uma cidade para outra se existisse uma aresta entre os vértices correspondentes. O referido itinerário ia-se marcando com um fio de lã, que se prendia à cidade inicial (ex: Dublin) e dava a volta no eixo de cada cidade por onde passava. O desafio proposto é possível e não muito díficil. Os especialistas podiam jogar fixando duas ou mais cidades como ponto de partida.

Como o dodecaedro regular de madeira é um pouco volumoso e díficil manejar, surgiu uma outra versão do mesmo jogo, agora como uma figura planificada (veja Figura 1.21).

Definição 1.28. Seja $G$ um grafo. Um caminho em $G$ que passa uma única vez por cada vértice de $G$ é chamado caminho Hamiltoniano. Se, além disso, o caminho começa e termina

\footnotetext{
${ }^{2}$ William Rowan Hamilton (1805-1865), matemático irlandês que contribuiu para o desenvolvimento da óptica, dinâmica e álgebra, em particular descobrindo a álgebra de quatérnios. De 1833 em diante, Hamilton adaptou seus métodos ópticos para o estudo de problemas de dinâmica. Dois dos principais artigos de Hamilton On a General Method in Dynamics foram publicados em 1834 e 1835 . No segundo destes, as equações de movimento de um sistema dinâmico são expressos em uma forma particularmente elegante (equações de movimento de Hamilton). A abordagem de Hamilton foi aperfeiçoada pelo matemático alemão Carl Jacobi, e sua importância tornou-se evidente no desenvolvimento da mecânica celeste e mecânica quântica. A Mecânica Hamiltoniana é subjacente á pesquisa contemporânea em geometria simplética (um campo de pesquisa em geometria algébrica) e da teoria de sistemas dinâmicos. De 1837 a 1846, Hamilton foi presidente da Real Academia Irlandesa. Em 1856, Hamilton investigou caminhos fechados ao longo das arestas de um dodecaedro (um dos sólidos platônicos) que passam cada uma dos vértice exatamente uma vez. Em teoria dos grafos tais caminhos são conhecidos hoje como ciclo Hamiltonianos.)
} 

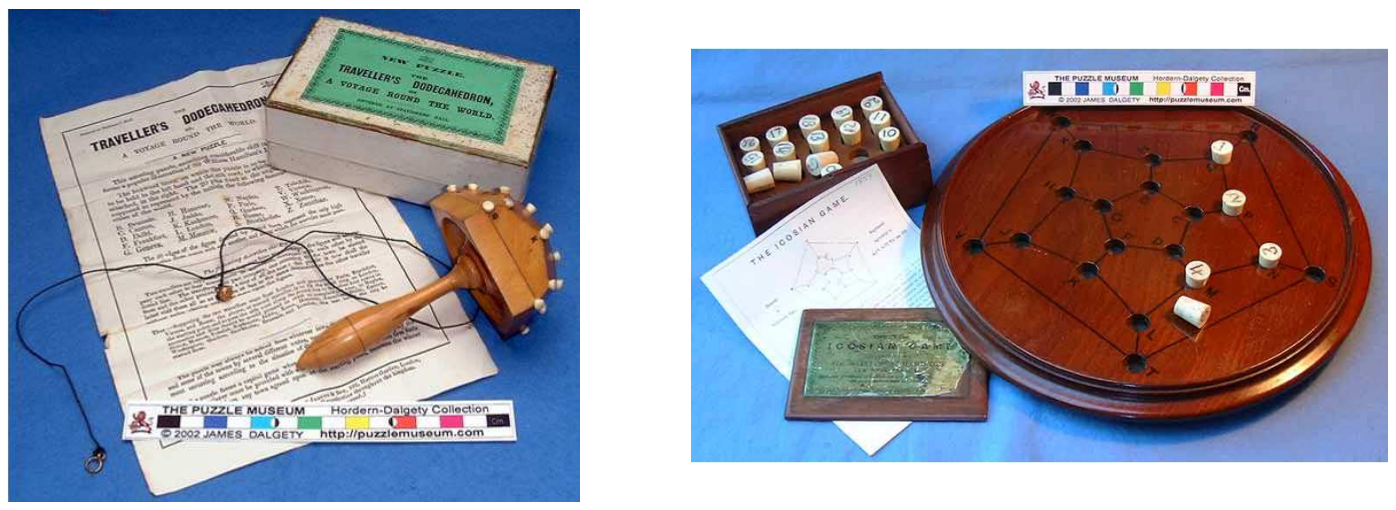

Figura 1.21: Icosain Game (Fonte: [4])

no mesmo vértice, o caminho é chamado ciclo Hamiltoniano. Por fim, se G possui um ciclo Hamiltoniano, dizemos que $G$ é um grafo Hamiltoniano.

Observe os dois grafos abaixo. O primeiro apresenta um ciclo Hamiltoniano, já o segundo não.
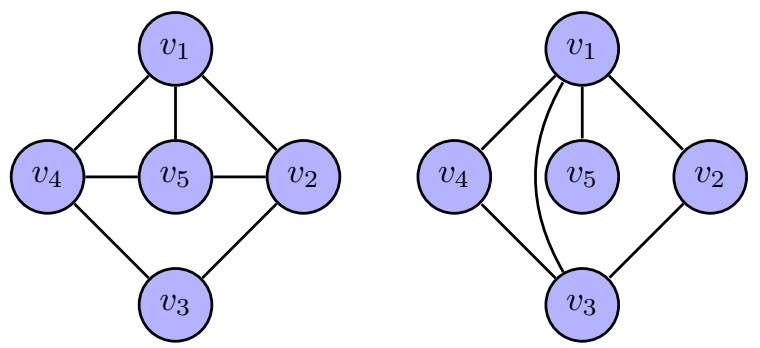

Em teoria de grafos, saber se um grafo é ou não Hamiltoniano é uma questão muita estudada, devido a sua aplicação em comunicação, transporte e planejamento. O próximo resultado apresenta uma condição suficiente para um grafo ser Hamiltoniano.

Teorema 1.29. (Dirac) Se $G$ é um grafo de ordem $n \geq 3$ tal que o $d(v) \geq n / 2$ para cada vértice $v$ de $G$, então $G$ é Hamiltoniano.

Demonstração. Suponha que a afirmação seja falsa. Então existe um grafo simples nãoHamiltoniano maximal $G$ de ordem $\mathrm{n} \geq 3$ que satisfaz a condição do teorema. Ou seja, (maximal no sentido de que) $G$ é não-Hamiltoniano, mas para qualquer par de vértices não adjacentes $u, v$ em $G$, temos que o grafo $G+u v$ (o grafo obtido pelo acréscimo da aresta $u v)$ é Hamiltoniano. Claramente $G$ não é completo (todo grafo completo com pelo menos 3 vértices é obviamente Hamiltoniano). Portanto, existem vértices $u$ e $v$ não adjacentes em $G$. Considere o grafo $H:=G+u v$. Pela maximalidade de $G$, segue que $H$ é Hamiltoniano. Logo, todo circuito Hamiltoniano em $H$ deve conter a aresta $u v$. Então $G$ tem um caminho Hamiltoniano, digamos

$$
P:=\left(u v_{1}, v_{1} v_{2}, \ldots, v_{n} v\right)
$$


Note que, se $v_{i}$ é adjacente a $u$, então $v_{i-1}$ não é adjacente a $v$, pois senão

$$
C=\left(v_{1} v_{i}, v_{i} v_{i+1}, \ldots, v_{n-1} v_{n}, v_{n} v_{i-1}, v_{i-1} v_{i-2}, \ldots, v_{2} v_{1}\right)
$$

seria um circuito Hamiltoniano em $G$, contrariando a escolha de $G$. Portanto, para todo vértice adjacente a $u$, existe um vértice de $V(G)$ tal que $v$ que não é adjacente a $v$. Mas neste caso,

$$
d(v) \leq n-1-d(u) .
$$

Como $d(u) \geq \frac{n}{2}$, temos que $d(v) \leq n-1-\frac{n}{2}=\frac{n}{2}-1$, uma contradição. Logo, a afirmação é verdadeira, e o teorema está provado.

O próximo resultado apresente uma outra condição suficiente para um grafo ser Hamiltoniano.

Teorema 1.30. (Ore) Seja $G$ um grafo simples de ordem $n \geq 3$. Se $d(u)+d(v) \geq n$, para todo par $u, v$ de vértices não adjacentes, então $G$ é Hamiltoniano.

Demonstração. Dado $G$ nas condições do Teorema, suponhamos $G$ não Hamiltoniano. Adicione em $G$, se possível, o maior número de arestas de modo que $G$ continue não Hamiltoniano. Após isto, qualquer aresta a mais tornará $G$ Hamiltoniano. Observe que com a adição destas arestas, ainda temos $d(u)+d(v) \geq n$. Seja $C=\left(v_{1} v_{2}, v_{2} v_{3}, \ldots, v_{n-1} v_{n}\right)$ um caminho $G$ que contém todos os vértices (tal caminho existe, pois com uma aresta a mais o grafo seria Hamiltoniano fornecendo assim um ciclo Hamiltoniano). Como $G$ não é Hamiltoniano, $C$ não é ciclo e então os vértices $v_{1}$ e $v_{n}$ não são adjacentes. Portanto, $d\left(v_{1}\right)+d\left(v_{n}\right) \geq n$ e de modo análogo ao teorema anterior, mostramos que existe algum vértice $v_{i}$ adjacente a $v_{1}$ tal que $v_{i-1}$ é adjacente à $v_{n}$. Deste modo obtemos um ciclo $\left(v_{1} v_{2}, v_{2} v_{3}, \ldots, v_{i-1} v_{n}, v_{n} v_{n-1} \ldots v_{i+1} v_{i}, v_{i} v_{1}\right)$ contendo todos os vértices de $G$, ou seja, um ciclo Hamiltoniano. Mas isso contradiz as hióteses sobre $G$ e portanto $G$ deve ser Hamiltoniano.

\subsection{Grafos valorados}

Definição 1.31. Um grafo valorado é uma terna $G=(V, A, T)$, onde $V$ é o conjunto de vértices do grafo, $A$ é o conjunto de arestas do grafo e $T$ é um conjunto de números reais que são atribuídos a cada uma das arestas ou aos vértices do grafo.

Para exemplificar o conceito de grafo valorado, vamos considerar o seguinte exemplo:

Exemplo 1.32. Considere a tabela de tarefas para a construção de uma casa de madeira. Qual é o tempo mínimo, em dias, para a construção desta casa?

No Capítulo 2 desta dissertação será feito uma análise da aplicação deste exemplo em sala de aula do ensino fundamental e médio. 


\begin{tabular}{|l|c|c|}
\hline Tarefas & Pré-requisitos & Dias \\
\hline 1. Limpeza do terreno & Nenhum & 4 \\
\hline 2. Produção e colocação da fundação & 1 & 3 \\
\hline 3. Produção e colocação da estrutura & 2 & 7 \\
\hline 4. Colocação das tábuas externas & 3 & 4 \\
\hline 5. Colocação do telhado & 3 & 6 \\
\hline 6 Instalação do encanamento e fiação & 4 e 5 & 6 \\
\hline 7. Colocação dos batentes de janelas e portas & 3 & 5 \\
\hline 8. Instalação das Janelas e portas & 6 & 5 \\
\hline 9. Pintura interior & 7 e 8 & 5 \\
\hline
\end{tabular}

Tabela 1.1: Tarefas a serem desenvolidas

A resolução do problema em questão trabalha a ideia de minimizar o tempo de construção, mas vale ressaltar a necessidade de garantir o tempo mínino para a execução de todas as tarefas.

Vamos começar com um grafo sem arestas e a medida que avançarmos no raciocínio completaremos o grafo. Os vértices correspondem ás tarefas a serem realizadas e indicaremos sobre cada aresta a duração de cada processo, constituindo-se assim um grafo valorado.
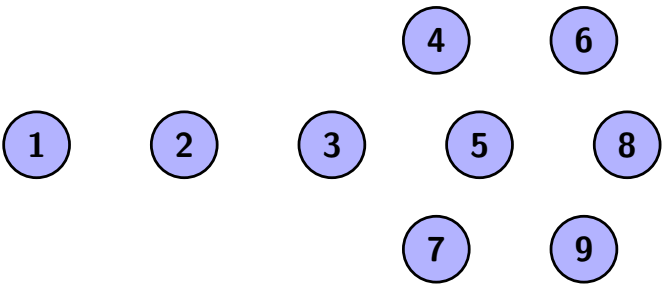

Figura 1.22

Inicialmente efetua-se a limpeza do terreno, para posteriormente dar continuidade no projeto. Estando concluída a limpeza do terreno, etapa programada para 4 dias, podemos

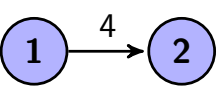

Figura 1.23: Primeira parte

prosseguir com a produção e colocação da fundação, pois, esta apresenta como pré-requisito a limpeza do terreno já efetuada. Sendo assim, a produção e colocação da fundação dará inicio no quinto dia de construção. De acordo com a tabela dos procedimentos, vemos que para a realização da tarefa 2 é necessário um período previsto de 3 dias. Após a conclusão do processo de produção e colocação da fundação já terá transcorrido sete dias de obra sendo 
assim, a produção e colocação das estruturas apenas poderá ocorrer no oitavo dia de trabalho, e com uma previsão de sete dias adicionais para a conclusão (Figura 1.24).

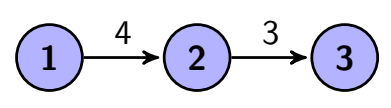

Figura 1.24: Segunda parte

Concluídos todos os trabalhos de produção das estruturas, duas novas equipes de construtores e serventes entram em ação para acelerar o processo, tendo em vista que o processo de colocação das tábuas externas, colocação do telhado e colocação das janelas e portas, são processos independentes, isto é, não é necessária a finalização de nenhum deles para que se prossiga o outro. Portanto, transcorridos 14 dias de construção, três novos procedimentos serão iniciados. Observe que para dar continuidade ao processo de construção,

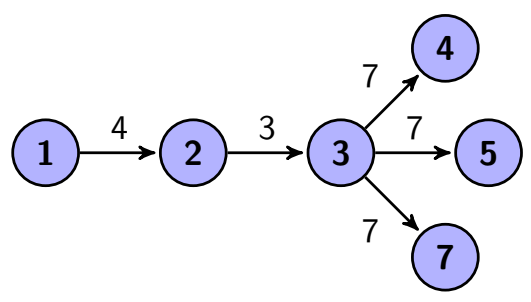

Figura 1.25: Terceira parte

com a instalação do encanamento e fiação, é necessário que os processos de colocação das tábuas externas e colocação dos telhados estejam concluídos. Por isto devemos observar que após concluído o processo de colocação das tábuas externas, foram transcorridos 18 dias do início das obras, de acordo com o grafo da Figura 1.26. Não podendo avançar ainda, pois como

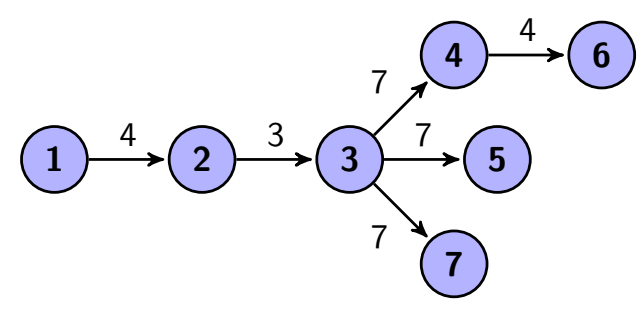

Figura 1.26: Quarta parte

foram transcorridos somente dezoito dias, não teremos encerrado o processo de colocação do telhado, e desta forma ainda deveremos esperar por mais dois dias para a conclusão desta etapa e, somente assim, iniciar o processo de instalação do encanamento e fiação no vigésimo primeiro dia de obra. Concluídas todas as etapas anteriores, a instalação de portas e janelas e somente terá início no vigésimo sétimo dia de obra, mesmo que a colocação de janelas e portas tenha sido realizada bem anteriormente. A instalação das mesmas tem previsão estimada de 5 dias de construção. O último passo na construção da casa, a pintura, depende 


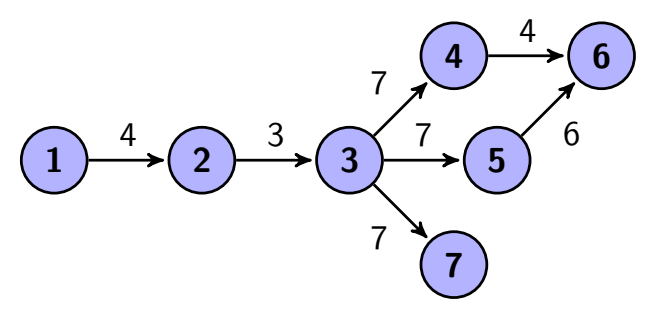

Figura 1.27: Quinta parte

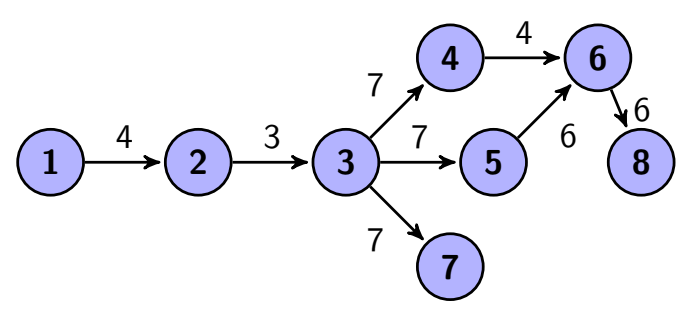

Figura 1.28: Sexta parte

da boa execução de todos os demais, representados pela colocação de portas e janelas, processo iniciado no décimo quinto dia de construção e finalizado no décimo nono dia, e também da instalação das mesmas, fato iniciado no vigésimo sétimo dia e finalizado no trigésimo primeiro. De acordo com as informações contidas na tabela inicial, a pintura da casa tem previsão de

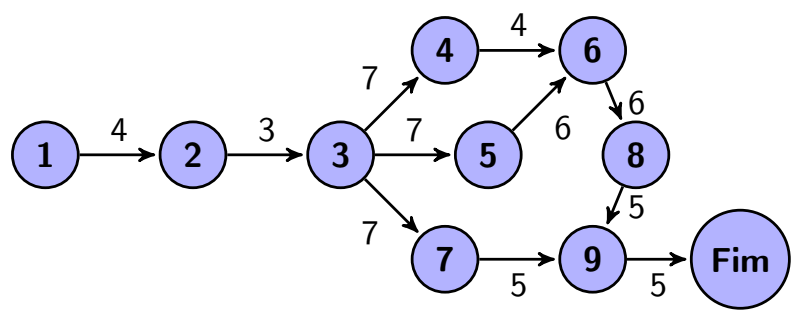

Figura 1.29: Sétima parte

cinco dias de duração, portanto a casa estando concluída transcorridos 36 dias de construção (Veja Figura 1.29).

Exercício 1.33. 1. As estradas que ligam à região Norte do Brasil são sempre um problema para quem necessita utilizar, visto que são escassas e de má qualidade. A região também possui uma grande bacia hidrográfica, o que impossibilita a construção de estradas em alguns trechos. Um candidato a presidência da república necessita se deslocar de Goiás, para Boa Vista, Roraima para cumprir alguns compromissos de sua campanha. Por questões econômicas ele decide fazer o percurso de carro, e para isso deve otimizar os quilometros, para que se possa gastar o menos possivel. Observando a figura 1.30, determine a distância a ser percorrida. 


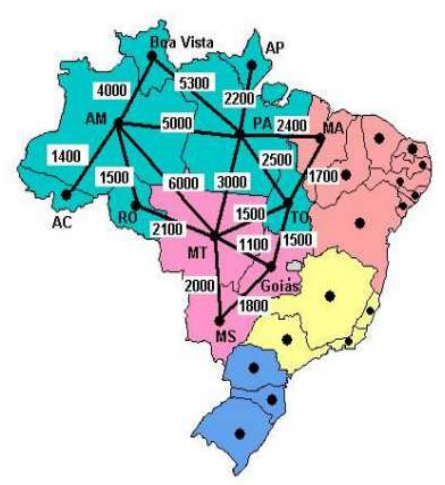

Figura 1.30: Estradas Região Norte

2. Considerando o mapa do Brasil apresentado na Figura 1.30 represente o grafo sobre os estados e suas divisas.

3. Seja o mapa com algumas cidades do Estado de São Paulo mostrado abaixo e uma tabela de distâncias.

\begin{tabular}{|c|c|c|c|c|c|c|c|c|}
\hline & Araçatuba & Pres. Venceslau & Pres. Prudente & Tupã & Marília & Assis & Bauru & Ourinhos \\
\hline Araçatuba & - & 150 & - & 90 & 110 & - & 160 & - \\
\hline Pres. Venceslau & 150 & - & 40 & 95 & - & - & - & - \\
\hline Pres. Prudente & - & 40 & - & 85 & - & 105 & - & - \\
\hline Tupã & 90 & 95 & 85 & - & 60 & 80 & - & - \\
\hline Marília & 110 & - & - & 60 & - & 85 & 65 & 80 \\
\hline Assis & - & - & 105 & 80 & 85 & - & - & 75 \\
\hline Bauru & 160 & - & - & - & 65 & - & - & 105 \\
\hline Ourinhos & - & - & - & - & 80 & 75 & 105 & - \\
\hline
\end{tabular}

(a) Calcule a distância e o caminho entre as cidades de Araçatuba e Ourinhos. Apresente o seu desenvolvimento.

(b) Com a privatização das estradas, praças de pedágios foram construídas em todas as rodovias. Nas rodovias de comprimento inferior a $100 \mathrm{~km}$, o pedágio custa $\mathrm{R} \$ 4,00$; caso contrário, o pedágio tem o valor de $\mathrm{R} \$ 5,00$. Apresente a solução que satisfaça as condições de distância e custo. 


\section{Problema do caixeiro-viajante}

O problema do caixeiro-viajante (PCV) é um problema na teoria dos grafos que nenhum método geral de solução é conhecido. Trata de um problema que exige o ciclo Hamiltoniano mais eficiente (ou seja, de menor distância/custo total) que um vendedor deve tomar por todas as $n$ cidades a serem visitadas por ele. Mais especificamente, dado um grafo completo valorado $G$, determinar o valor do menor ciclo Hamiltoniano de $G$.

\subsection{Métodos de solução para o PCV}

Um caixeiro viajante que tem cinco clientes em cinco cidades, que denotaremos por, $A, B$, $C, D$ e $E$. Ele precisa planejar uma viajem a negócios partindo da cidade $A$, e retornando a mesma cidade, passando por todas as cidades uma única vez.

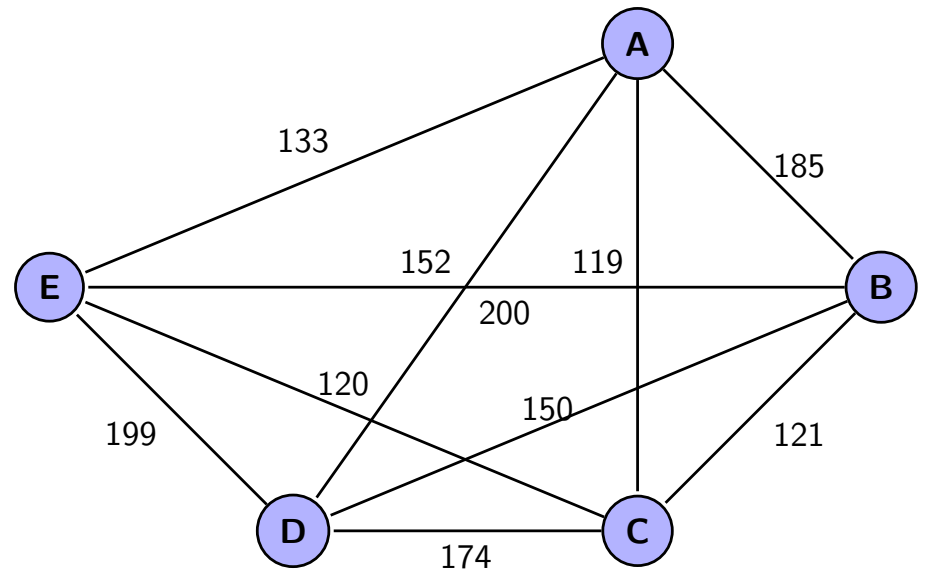

O grafo acima representa o custo de cada viajem, independente do sentido, também representados na tabela abaixo.

\begin{tabular}{|c|c|c|c|c|c|}
\hline & $\mathrm{A}$ & $\mathrm{B}$ & $\mathrm{C}$ & $\mathrm{D}$ & $\mathrm{E}$ \\
\hline $\mathrm{A}$ & $\mathrm{X}$ & 185 & 119 & 152 & 133 \\
\hline $\mathrm{B}$ & 185 & $\mathrm{X}$ & 121 & 150 & 200 \\
\hline $\mathrm{C}$ & 119 & 121 & $\mathrm{X}$ & 174 & 120 \\
\hline $\mathrm{D}$ & 152 & 150 & 174 & $\mathrm{X}$ & 199 \\
\hline $\mathrm{E}$ & 133 & 200 & 120 & 199 & $\mathrm{X}$ \\
\hline
\end{tabular}

\section{Métodos Exatos}

Consiste basicamente em fazer um lista com todas as alternativas possível de caminhos, por isto torna-se um método exaustivo, e em muitos casos sua complexidade é fatorial e em casos como grafos com altos números de vértices. Para facilitar este método, utiliza-se uma técnica 
chamada "branch-and-bound", que consiste em expandir os nós e cortar caminhos de pesquisa que não são promissores.

Exemplo 1.34. Utilizar o método exaustivo para resolver o problema do caixeiro-viajante é calcular os valores dos $4 !=24$ ciclos Hamiltonianos possiveis em $K_{5}$. Como não nos interessa o sentido do ciclo, observa-se a tabela abaixo com todos os 12 ciclos possiveis distintos.

\begin{tabular}{|c|c|c|}
\hline Ciclo Hamiltoniano & Custo total (R\$) & Ciclo inverso \\
\hline$A-B-C-D-E-A$ & $185+121+174+199+133=812$ & $A-E-D-C-B-A$ \\
\hline$A-B-C-E-D-A$ & $185+121+120+199+152=777$ & $A-D-E-C-B-A$ \\
\hline$A-B-D-C-E-A$ & $185+150+174+120+133=762$ & $A-E-C-D-B-A$ \\
\hline$A-B-D-E-C-A$ & $185+150+199+120+119=773$ & $A-C-E-D-B-A$ \\
\hline$A-B-E-C-D-A$ & $185+200+120+174+152=831$ & $A-D-C-E-B-A$ \\
\hline$A-B-E-D-C-A$ & $185+200+199+174+119=877$ & $A-C-D-E-B-A$ \\
\hline$A-C-B-D-E-A$ & $119+121+150+199+133=722$ & $A-E-D-B-C-A$ \\
\hline$A-C-B-E-D-A$ & $119+121+200+199+152=791$ & $A-D-E-B-C-A$ \\
\hline$A-C-D-B-E-A$ & $119+174+150+200+133=776$ & $A-E-B-D-C-A$ \\
\hline$A-C-E-B-D-A$ & $119+120+200+150+152=741$ & $A-D-B-E-C-A$ \\
\hline$A-D-B-C-E-A$ & $152+150+121+120+133=676$ & $A-E-C-B-D-A$ \\
\hline$A-D-C-B-E-A$ & $152+174+121+200+133=780$ & $A-E-B-C-D-A$ \\
\hline
\end{tabular}

Verificando, assim, que obtemos exatamente um ciclo ótimo, e consequentemente o seu inverso também. Em qualquer um dos casos o caixeiro-viajante gasta $R \$ 676,00$ na sua viagem.

Este método é, em geral, impossível de implementar, já que o números de operações é da ordem $(n-1)$ !, para $K_{n}$. Até mesmo um supercomputador capaz de fazer bilhões $\left(10^{15}\right)$ de cálculos por segundo, levaria 10 meses para $n=24,20$ anos para $n=25,500$ anos para $n=26$ e 284 milhões de anos para $n=30$.

\section{Métodos Heurísticos}

Em Ciência da Computação, normalmente existem duas propriedades principais na criação e elaboração de algoritmos:

- fazer o algoritmo ter um tempo de execução sempre aceitável;

- ser a solução ótima ou provavelmente boa para o problema em todos os casos.

No entanto, um algoritmo heurístico não cumpre uma dessas propriedades, podendo ser ou um algoritmo que encontra boas soluções a maioria das vezes, mas não tem garantias de que sempre encontrará ou um algoritmo que tem processamento rápido, mas não tem provas de que será rápido para todas as situações. 


\section{Método do Vizinho Mais Próximo (método guloso)}

Escolhe-se um vértice e a aresta de menor peso incidente nesse vértice. Esta aresta determina um outro vértice. De cada novo vértice escolhe-se a aresta de menor peso, de entre as arestas que são incidentes nesse vértice e num vértice que ainda não foi escolhido. No final, regressa-se ao vértice inicial.

Exemplo 1.35. No caso do exemplo do caixeiro-viajante, por este algoritmo ele começa pelo vértice $A$. De $A$ vai para $C$, de $C$ para $E$, depois para $D$ e finalmente para $B$, de onde regressa $a A$.

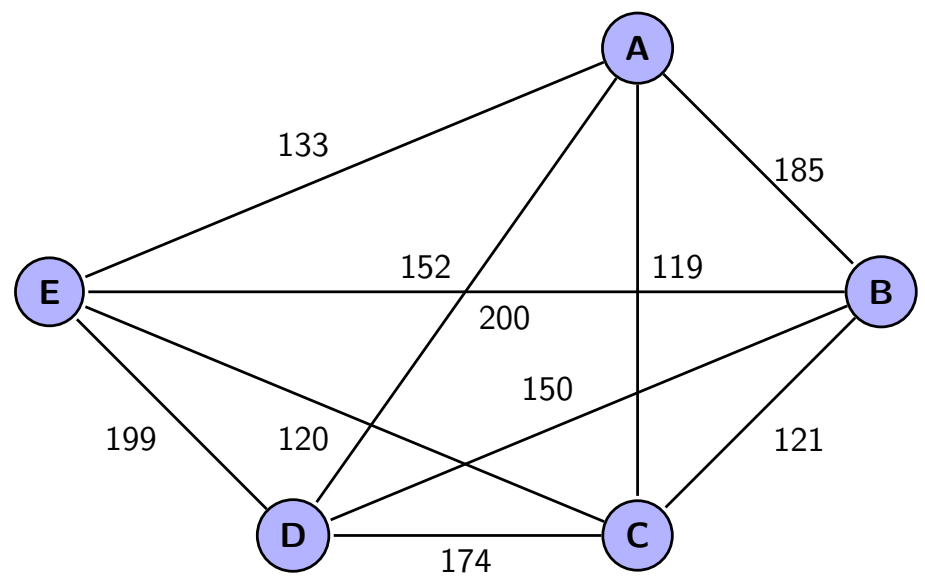

Com o custo determinado pelos seguintes pesos, $119+120+199+150+185=773 \mathrm{O}$ custo desta viagem é de $\mathrm{R} \$ 773,00$

O método do vizinho mais próximo é muito mais rápido do que que o método de exaustão, embora não produza, em geral, uma solução optimal. No caso do exemplo anterior, o custo adicional é de $\mathrm{R} \$ 97,00$ e o erro relativo é de $97 / 676 \approx 14,3 \%$.

Até que ponto o algoritmo Guloso é suficientemente eficiente?

Por exemplo, se $n=30$ e demorarmos um minuto em cada operação, conseguiremos a solução deste algoritmo em meia hora, tempo suficientemente curto quando comparado pelo método da exaustão utilizando um supercomputador gastariamos mais de 200 milhões de anos. Ponto forte do método Guloso.

Exemplo 1.36. No exemplo do caixeiro-viajante e cinco cidades, suponhamos que o caixeiroviajante consiga ampliar seu negócio e consiga mais cinco novos clientes em mais cinco cidades diferentes.

$O$ custo das viagens entre as cidades está representado abaixo, em forma de um grafo e em forma de tabela.

Com o total de dez cidades a serem visitadas, a quantidade de caminhos possiveis, aumenta significativamente, como podemos observar. 


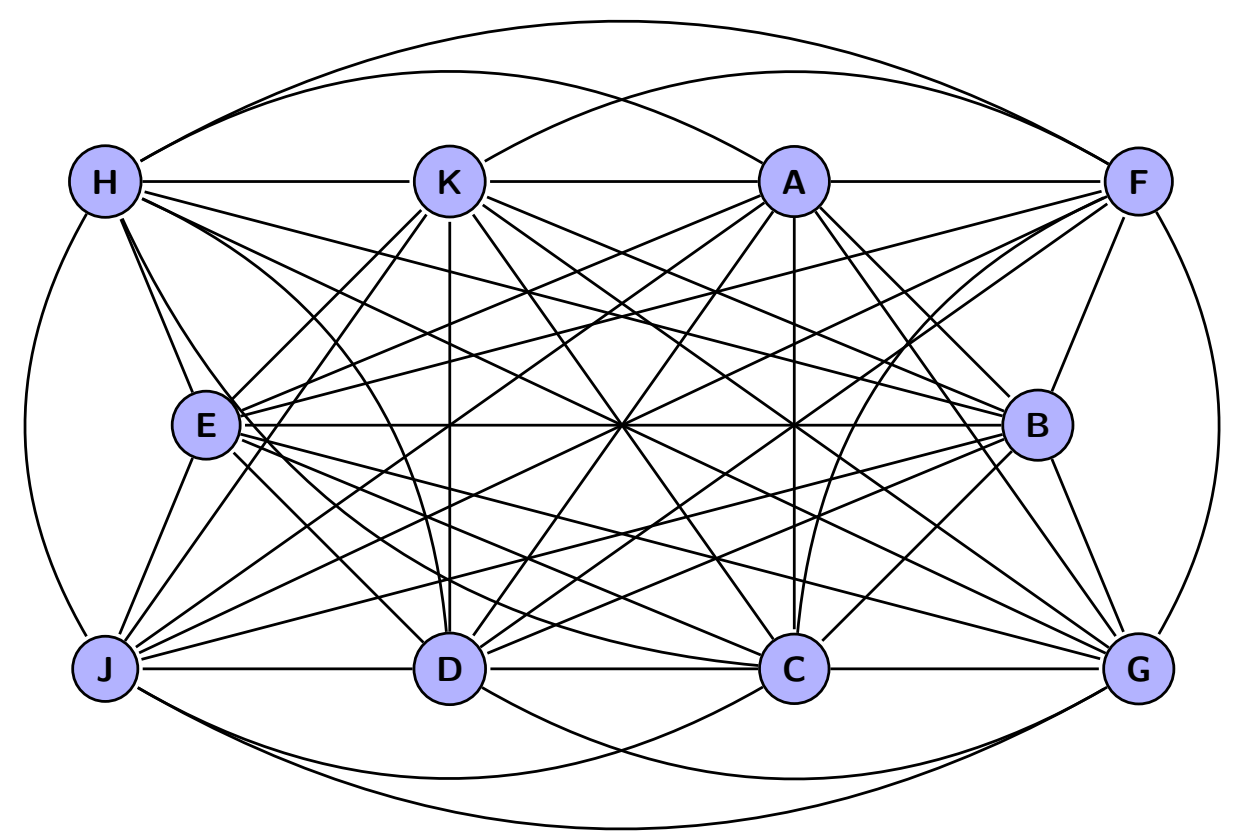

\begin{tabular}{|c|c|c|c|c|c|c|c|c|c|c|}
\hline & $\mathrm{A}$ & $\mathrm{B}$ & $\mathrm{C}$ & $\mathrm{D}$ & $\mathrm{E}$ & $\mathrm{F}$ & $\mathrm{G}$ & $\mathrm{H}$ & $\mathrm{J}$ & $\mathrm{K}$ \\
\hline $\mathrm{A}$ & $\mathrm{X}$ & 185 & 119 & 152 & 133 & 321 & 297 & 277 & 412 & 381 \\
\hline $\mathrm{B}$ & 185 & $\mathrm{X}$ & 121 & 150 & 200 & 404 & 458 & 492 & 379 & 427 \\
\hline $\mathrm{C}$ & 119 & 121 & $\mathrm{X}$ & 174 & 120 & 332 & 439 & 348 & 245 & 443 \\
\hline $\mathrm{D}$ & 152 & 150 & 174 & $\mathrm{X}$ & 199 & 495 & 480 & 500 & 454 & 489 \\
\hline $\mathrm{E}$ & 133 & 200 & 120 & 199 & $\mathrm{X}$ & 315 & 463 & 204 & 396 & 487 \\
\hline $\mathrm{F}$ & 321 & 404 & 332 & 495 & 315 & $\mathrm{X}$ & 356 & 211 & 369 & 222 \\
\hline $\mathrm{G}$ & 297 & 458 & 439 & 480 & 463 & 356 & $\mathrm{X}$ & 471 & 241 & 235 \\
\hline $\mathrm{H}$ & 277 & 492 & 348 & 500 & 204 & 211 & 471 & $\mathrm{X}$ & 283 & 478 \\
\hline $\mathrm{J}$ & 412 & 379 & 245 & 454 & 396 & 369 & 241 & 283 & $\mathrm{X}$ & 304 \\
\hline $\mathrm{K}$ & 381 & 427 & 443 & 489 & 487 & 222 & 235 & 478 & 304 & $\mathrm{X}$ \\
\hline
\end{tabular}

Observamos que para este problema temos que calcular o peso de $9 !=362880$ ciclos Hamiltonianos. Considerando o tempo de trinta segundo para a realização do ciclo, levariamos 3024 horas, o que representa mais de 4 meses de trabalho, 24 horas por dia, 7 dias por semana.

Recorremos então para o método guloso obtemos o ciclo,

$$
A-C-E-D-B-J-G-K-F-H-A
$$

cujo o custo é de $\mathrm{R} \$ 2153,00$. E utilizando um bom computador verificamos que a solução optimal é de R\$1914,00.

Sendo assim o erro relativo é de $(2153-1914) / 1914 \approx 12,5 \%$ 


\section{Método do Vizinho Mais Próximo com Repetição}

Este algoritmo funciona como o algoritmo do vizinho mais próximo descrito anteriormente, sendo a diferença que este último é implementado tantas vezes quantos os vértices do grafo, tomando de cada vez um vértice diferente como vértice inicial. Depois, é escolhido o ciclo de peso menor como resultado final do algoritmo. Se for obtido o ciclo

$$
X_{1}, X_{2}, \ldots, X_{k}, \operatorname{com} X_{1}=X_{k},
$$

como resultado deste método, e quisermos um ciclo de vértice inicial $X_{j}$, tomamos o ciclo

$$
X_{j}, X_{j+1}, \ldots, X_{k}=X_{1}, X_{2}, \ldots, X_{j-1}
$$

cujo peso é o mesmo do ciclo (1.1).

Exemplo 1.37. Consideremos novamente o exemplo do caixeiro-viajante e cinco cidades. Aplicando o algoritmo do vizinho mais próximo com repetição, obtemos sucessivamente os ciclos:

\begin{tabular}{|c|c|}
\hline Ciclo & custo $(\mathrm{R} \$)$ \\
\hline A-C-E-D-B-A & 773 \\
\hline B-C-A-E-D-B & 722 \\
\hline C-A-E-D-B-C & 722 \\
\hline D-B-C-A-E-D & 722 \\
\hline E-C-A-D-B-E & 741 \\
\hline
\end{tabular}

Assim, este algoritmo escolhe o ciclo $B-C-A-E-D-B=C-A-E-D-B-C=$ $D-B-C-A-E-D$, cujo custo é de $\mathrm{R} \$ 722,00$. Como sabemos, este não é um ciclo optimal, mas o resultado é mais satisfatório do que o obtido usando o algoritmo do vizinho mais próximo (sem repetição) começando em A. Sendo assim o erro relativo é de $(722-676) / 676 \approx 6,8 \%$

\section{Algoritmo de Kruskal}

O algoritmo de Kruskal consiste em escolher arestas, (adjacentes ou soltas) que apresentam os menores pesos. Também conhecido por algoritmo guloso pois, a sua solução pode se aproximar ou não da solução ótima. Para a realização de tal algoritmo, devemos obedecer as seguintes regras:

1. não é permitido formar um ciclo, a não ser que já tivermos percorridos todos os vértices;

2. não é permitido que das arestas escolhidas três delas sejam incidentes em um mesmo vértice. 


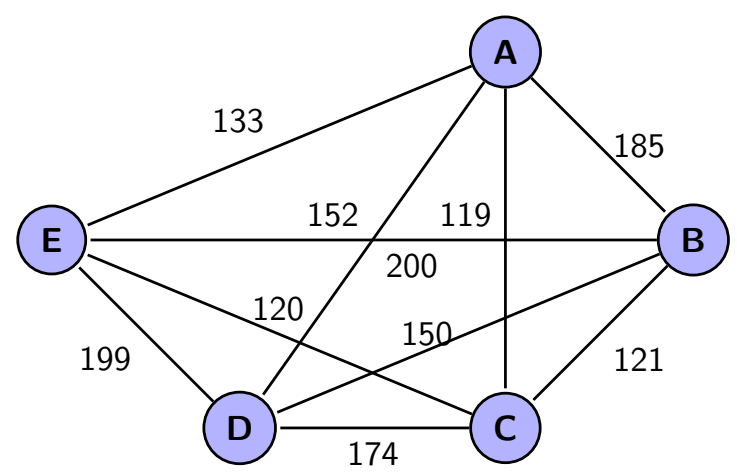

Exemplo 1.38. (o caxeiro-viajante e cinco cidades). Pelo Algoritmo de Kruskal;

Inicialmente temos as arestas $a-c=119$ representada pela Figura 1.31 e a aresta $c-e=120$, representada pela Figura 1.32.

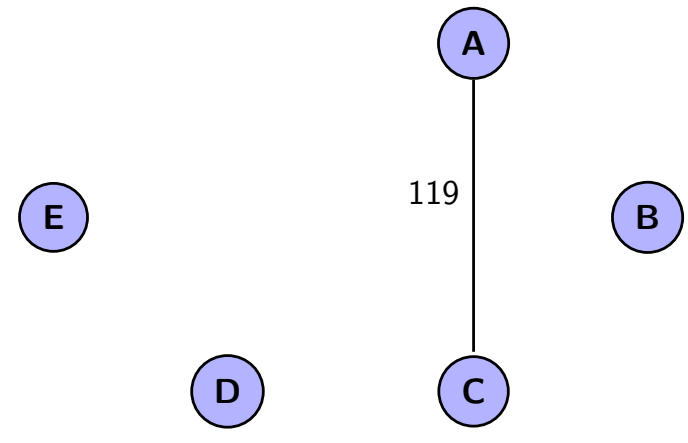

Figura 1.31

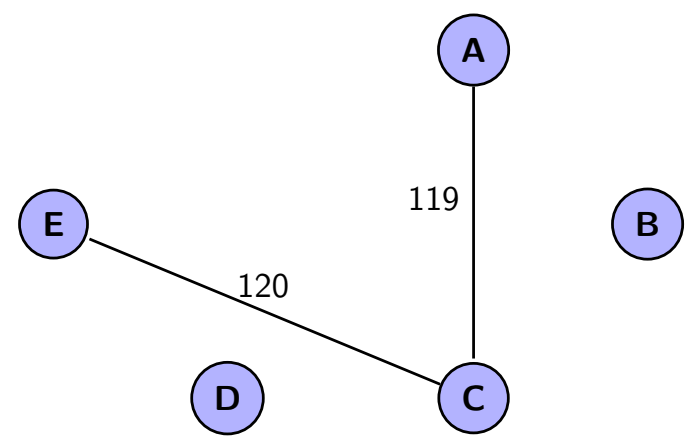

Figura 1.32

Neste momento prosseguiríamos com a aresta $b-c=121$ como a de menor peso, porém para está escolha, se contraria a segunda regra de Kruskal (três arestas incidêntes em um mesmo vértice). Prosseguindo temos a aresta $e-a=133$ porém caso seja escolhida esta contraria a primeira regra de Kruskal (formar um ciclo antes de percorrer todos os vértices). Sendo assim partimos para a aresta $b \rightarrow d \Rightarrow 150$, representada pela Figura 1.33 e a próxima aresta $e \rightarrow b \Rightarrow 152$, representada pela Figura 1.34. 


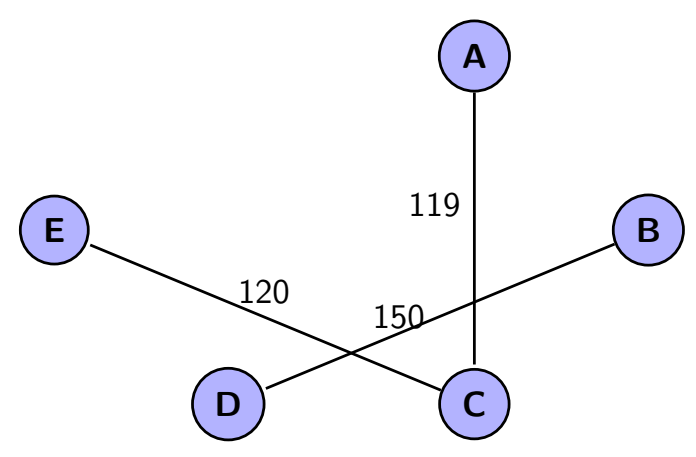

Figura 1.33

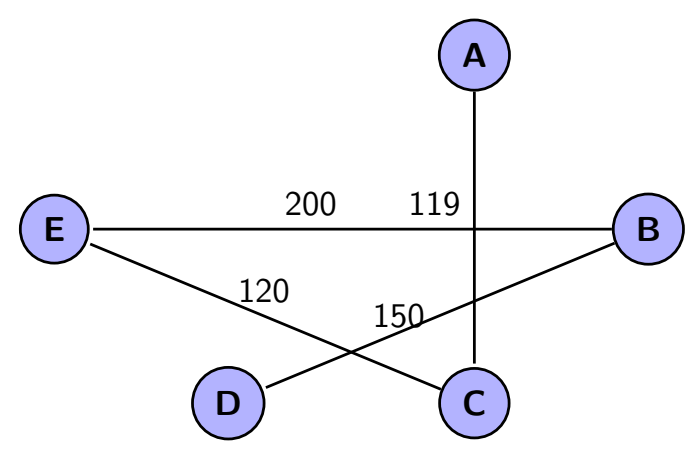

Figura 1.34

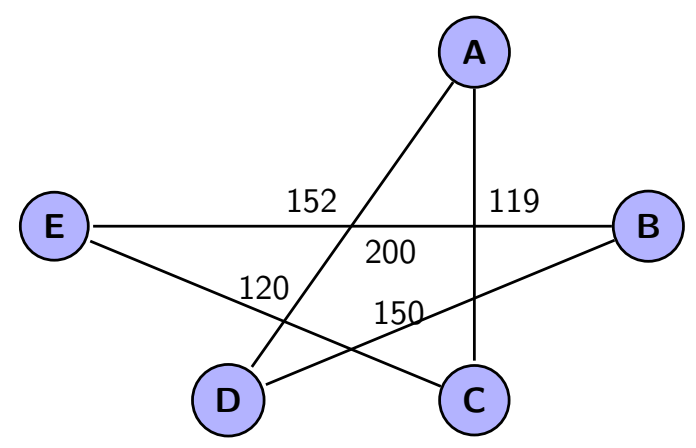

Figura 1.35

As arestas $c-d=174$ e $a-b=185$ não satisfazem a segunda condição de Kruskal. A aresta $d-e=199$ não satisfaz a primeira e nem a segunda condição de Kruskal. Sendo assim, para fecharmos a condição do problema temos a aresta $d \rightarrow a \Rightarrow 200$, representada na Figura 1.35. Portanto, para a conclusão do percurso, o caixeiro-viajante irá percorrer o ciclo $A-C-E-B-D-A$ em um percurso de custo total de $\mathrm{R} \$ 741,00$.

Este com erro relativo de $(741-676) / 676 \approx 9,6 \%$. 


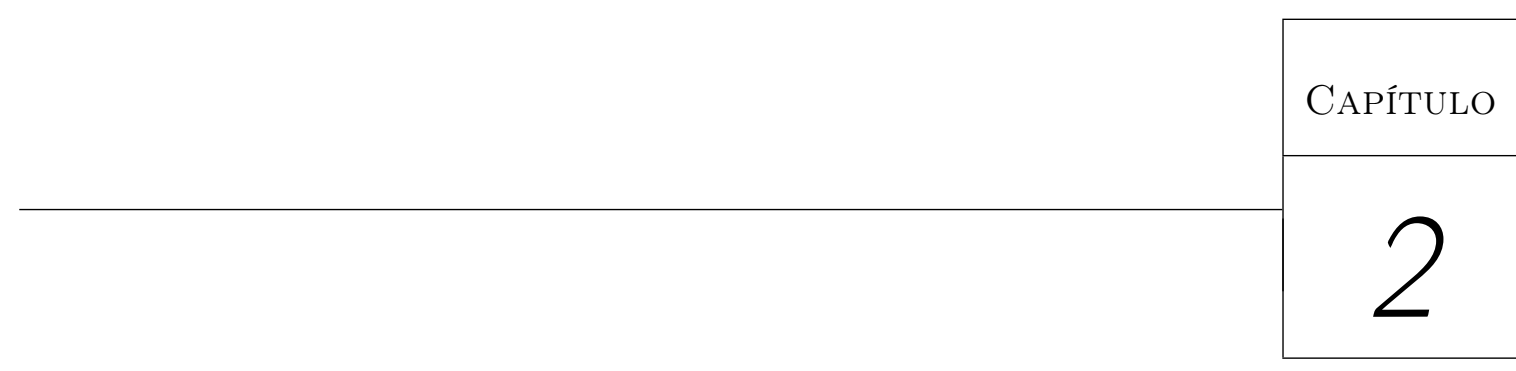

\section{Roteiro de aula}

\section{Introdução}

Este capítulo é dedicado a descrever a atividade realizada em sala de aula envolvendo o conceito de grafo. Para que se realizassem as atividades com um melhor rendimento dos alunos, foram elaboradas fichas de atividades para que se pudessem analisar detalhes sobre a resolução e linha de raciocínio utilizada por eles. Para a elaboração das fichas foram utilizadas questões do banco de questões da OBMEP [7] e algumas versões dos exemplos apresentados no Capítulo 1. Após uma breve descrição da escola e dos alunos envolvidos, descreveremos os procedimentos para a aplicação, os resultados obtidos, uma analise do desempenho dos estudantes e as considerações finais.

\subsection{Descrição da Comunidade Avaiense}

Localizada no centro do Estado de São Paulo, a pequena cidade de Avaí, (4959 habitantes segundo ultimo censo do IBGE em 2010) conta com cinco escolas estaduais, sendo apenas uma localizada no perímetro urbano, as demais são localizadas na zona rural do municipío mais precisamente em quatro aldeias indígenas (Aldeia Ekerua, Aldeia Kopenoti, Aldeia Nimuendaju e Aldeia Teregua), porém estas atendem apenas alunos indigenas e conta apenas com o ensino fundamental, sendo assim, quando estes chegam ao ensino médio, são matriculados na Escola Estadual de Ensino Fundamental e Médio Doutor Anis Dabus localizada no centro do município de Avaí. 


\subsection{Uma breve descrição da escola e dos alunos participantes}

A Escola Estadual de Ensino Fundamental e Médio Doutor Anis Dabus fica localizada na rua Doutor Pedro da Rocha Braga, n. 372 no centro do município de Avaí. Os alunos são atendidos no três períodos, matutino, vespertino e noturno. Sendo que o período da manhã é composto por uma turma do sexto ano, uma turma do sétimo ano, uma turma do oitavo ano e duas turmas de oitava série, além de uma segunda série e uma terceira série do ensino médio. Já o período da tarde é composto de uma turma de sexto ano, uma turma de sétimo ano, duas turmas de oitavo ano e uma oitava série do ensino fundamental, além de uma turma da primeira série, uma turma da segunda série e uma turma de terceira série do ensino médio. O período noturno é composto de uma turma da primeira série, uma turma de segunda série e uma turma da terceira série, ambas do ensino médio. Com turmas médias de 35 alunos. O espaço físico da escola e composto por nove salas de aula, um laboratório de informática com 25 novos computadores, sala de leitura e biblioteca, uma quadra poliesportiva coberta, uma sala de vídeo com televisão de 51 polegadas e DVD, refeitório, além da parte administrativa da escola que é composta de uma secretaria, uma sala para diretoria e vice diretoria, uma sala para a coordenação pedagógica, e uma sala para professores. Os alunos atendidos pela escola são distribuídos da seguinte maneira: no período matutino a maioria dos estudantes é da zona urbana da cidade, no período vespertino a grande parte alunos atendidos é da zona rural, além dos indigenas já mencionados, o período noturno fica dedicado aos alunos da zona rural ou urbana que trabalham durante o dia.

\section{Organização da sala de aula}

As atividades foram aplicadas em duas turmas, sendo uma delas uma oitava série do ensino fundamental e uma terceira série do ensino médio, ambas no período da manhã, uma vez que o professor que defende esta dissertação de mestrado, leciona apenas neste turno. Inicialmente se pensou em aplicar tais atividades em duas séries distintas para avaliar as diferentes formas de raciocínio. Em ambas as salas foram aplicadas em uma única aula dupla de 50 minutos cada, totalizando 100 minutos de atividades. Para uma melhor realização das atividades as turmas foram divididas em duplas.

Sendo que a oitava série ficou dividida em 14 duplas, enquanto a terceira série em 16 duplas, totalizando assim 30 duplas para serem avaliadas.

A proposta era que a atividade fosse entregue sem uma apresentação formal dos conceitos de grafo para avaliar o conhecimento prévio dos alunos sobre o assunto. Somente após a análise das folhas com as atividades é que o professor realizaria uma explanação sobre os aspectos teóricos envolvidos para que os alunos pudessem resolver com maior facilidade. 


\section{Folhas de Atividades}

A folha de atividade foi dividida em dois exercícios, sendo que o primeiro era subdividido em três itens, onde para os dois primeiros itens os estudantes deveriam encontrar um ciclo hamiltoniano, e para o terceiro item, o contrário, mostrar que não existem tal ciclo.

Por se tratar de um item básico, para os itens $a$ e $b$ nada foi mencionado, apenas orientados a ler e interpretar o enunciado do problema.

1. Leia e resolva as questões abaixo

a) A doutora Maria Amélia viaja para atender seus pacientes. Em seu primeiro dia de trabalho, ela tem que atender pacientes nas cidades Anápolis, Beápolis, Ceápolis, Deápolis e Enápolis. As cidades são ligadas por estradas, como mostra a figura abaixo. Para atender os pacientes mais rapidamente, a doutora Maria Amélia precisa passar por cada cidade exatamente uma vez, e no fim voltar para a cidade por onde começou o percurso. A doutora começa em Anápolis. Mostre como ela pode fazer isto!

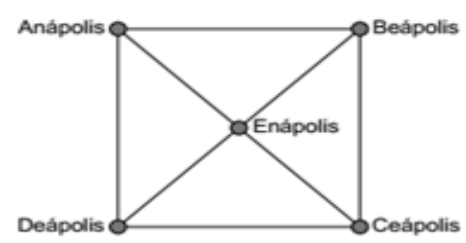

b) A doutora Maria Amélia precisa fazer o mesmo, mas agora uma estrada foi interditada para manutenção. Mostre que a doutora ainda pode fazer o percurso descrito anteriormente passando apenas uma vez por cada cidade e retornando para a cidade de partida, Anápolis.

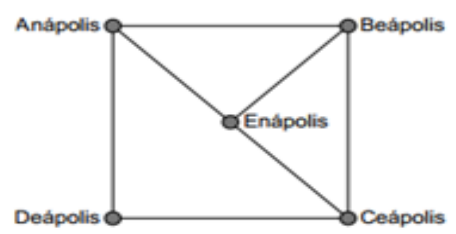

Figura 2.1: Problema 1 itens $a$ e $b$

Esperava-se que os alunos não apresentassem problemas para a solução dos mesmos. Vejamos uma resposta esperada para cada item. 
c) Com o crescimento populacional, surgiram novas cidades, Efeápolis, Geápolis, Agápolis e lápolis como mostrado abaixo. As estradas que estavam em manutenção voltaram a ser transitáveis. Mostre que neste caso não há solução para o problema, ou seja, não há como a doutora sair de Anápolis, passar por cada uma das outras cidades exatamente uma vez, e então voltar para Anápolis.

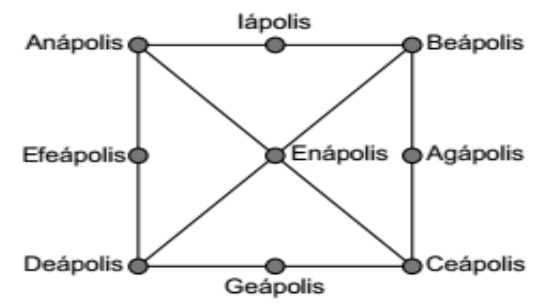

Figura 2.2: Problema 1 item $c$

1. (a) Uma simples sequência de flechas já seria considerada resposta certa, porém vamos enunciar a resposta com a sequência das iniciais de cada uma das cidades em questão

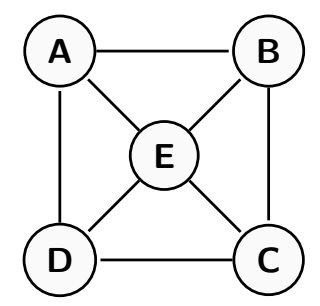

Figura 2.3: Representação problema 1 item $a$

Temos como solução de tal problema o ciclo hamiltoniano $A-D-C-B-E-A$.

(b) Para este item, caso a escolha do ciclo hamiltoniano do item anterior não contenha a aresta $D E$ o ciclo pode permanecer o mesmo.

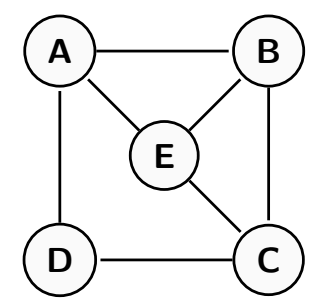

Figura 2.4: Representação problema 1 item $b$ 
Uma maneira de mostrar soluções distintas para o problema, vamos citar o ciclo hamiltoniano $A-B-E-C-D-A$.

(c) Pela falta de hábito dos alunos em formalizar uma demonstração, deve-se mencionar que eles podem fazer por dois métodos, o mais simples de entender, porém de maior complexidade para realizar, seria tentar exaustivamente todos os caminhos possíveis. O outro método seria encontrar uma maneira de mostrar a indisponibilidade de tal caminho.

Vejamos uma demonstração aceitável.

Chamamos de $A$ os vértices já existentes nas situações anteriores, e $N$ os novos vértices.

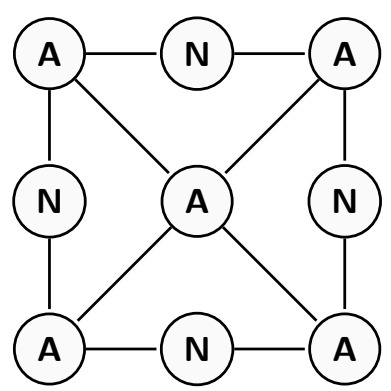

Figura 2.5

Para que se realize o caminho proposto é necessário que se percorra cada vértice uma única vez, sendo assim teríamos 5 vértices antigos e 4 novos. Observando que de cada ponto antigo somente é possível caminhar para um vértice novo, assim como de um ponto novo, somente é possível seguir para um antigo. Portanto se fosse possível sair de um vértice antigo e retornar para ele, deveríamos ter uma sequência alternada de $A, N, A, N, A, N, \ldots$, sempre encerraríamos em um vértice novo, para depois retornar ao inicial, e para que isto ocorra deveríamos ter uma mesma quantidade de vértices novos e antigos, o que contradiz a situação inicial, onde destacamos a existência de 5 vértices antigos e 4 novos! Portanto, não é possível que tal caminho exista.

Na segunda parte da atividade foi apresentado um problema sobre a construção de uma casa de madeira. Como tarefa, os alunos deveriam determinar o tempo de construção por duas empresas concorrentes e decidir qual realizaria a construção em menor tempo. Para isso, os alunos deveriam atentar-se ao fato de que alguns passos de construção poderiam ser feitos simultaneamente, com isso o tempo de realização da obra não seria simplesmente a soma da duração de cada passo.

Nessa atividade os alunos deveriam usar a noção da representação em grafo para melhor visualizar o andamento dos passos da construção. Já era esperado que os alunos apresentassem uma maior dificuldade para a realização dessa atividade, justamente pela falta de conhecimento da teoria dos grafos. 
2. Com as proximidades da Copa do Mundo da FIFA a ser realizada no Brasil neste ano de 2014, o governo federal adotou a seguinte ideia, construirá casas de madeira, que servirăo como estandes para uma grande exposição sobre as principais características culturais de todas as regiões como danças, comidas típicas, e belezas naturais entre outras, podendo assim mostrar um pouco da diversificada cultura do país. Para participar deste processo duas grandes empresas se inscreveram para a licitação, a PATRIMONIO BRASIL e CULTURA SEM LIMITES, de modo que após o processo burocrático verificou-se um empates nas questões de valores, e que devido a isso, e a proximidade do evento, optou-se pela empresa que realizar a obra em menos tempo, pois ambas as empresas conta com um pequeno número de funcionários e que só poderia construir uma casa por vez.

Abaixo encontramos tabela com a descrição do projeto e o tempo necessário para a sua realização.

\begin{tabular}{|c|c|c|}
\hline \multicolumn{3}{|l|}{ PATRIMONIOBRASIL } \\
\hline Tarefas & Pré-Requisitos & Dias \\
\hline 1. Limpeza do Terreno & Nenhum & 4 \\
\hline 2. Produção e Colocação da Fundação & 1 & 3 \\
\hline 3. Produção da Estrutura & 2 & 7 \\
\hline 4. Colocação das tábuas externas & 3 & 4 \\
\hline 5. Colocação do Telhado & 3 & 6 \\
\hline 6. Instalação dos encanamentos e fiação & 4 e 5 & 6 \\
\hline 7. Colocação dos batentes de portas e janelas & 3 & 5 \\
\hline 8. Instalacão das Portas e Janelas & 6 & 5 \\
\hline 9. Pintura Interior & 7 e 8 & 5 \\
\hline
\end{tabular}

\begin{tabular}{|c|l|l|}
\hline \multicolumn{2}{|c|}{ CULTURA SEM LIMITES } \\
\hline Tarefas & Pré-Requisitos & Dias \\
\hline 1. Limpeza do Terreno & Nenhum & 5 \\
\hline 2. Produção e Colocação da Fundação & 1 & 4 \\
\hline 3. Produção da Estrutura & 2 & 5 \\
\hline 4. Colocação das tábuas externas & 3 & 4 \\
\hline 5. Colocação do Telhado & 3 & 7 \\
\hline 6. Instalação dos encanamentos e fiação & 4 e 5 & 3 \\
\hline 7. Colocação dos batentes de portas e janelas & 3 & 8 \\
\hline 8. Instalação das Portas e Janelas & 6 & 3 \\
\hline 9. Pintura Interior & 7 e 8 & 2 \\
\hline
\end{tabular}

a) Atento de que todos os passos devem ser cumpridos e nenhum tem como ser acelerado, determine qual a empresa foi vencedora do processo de licitação.

b) Considerando que a empresa vencedora teve um problema com o funcionário responsável pela colocação dos batentes das portas e janelas, e que este se manteve em greve por oito dias, somente quando sua situação foi regularizada este voltou ao serviço, determine quantos dias à obra foi atrasada.

Figura 2.6: Problema 2 itens $a$ e $b$

2. No que segue, apresentamos um modo de resolução que poderia ser adotado pelos alunos.

(a) Determinação da empresa vencedora. 
- Iniciamos com a "PATRIMONIOBRASIL"

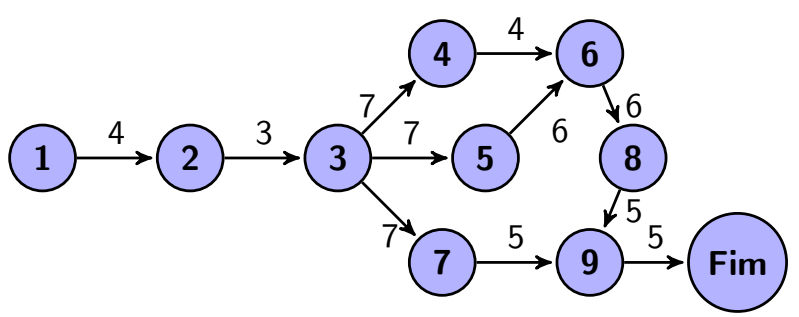

Figura 2.7: Grafo empresa "PATRIMONIOBRASIL"

Tarefa 1: 4 dias

Tarefa $2: 3+4=7$ dias

Tarefa 3: $7+7=14$ dias

Tarefa $4: 4+14=18$ dias

Tarefa 5: $6+14=20$ dias

Tarefa $6: \max ($ TAREFA 4 , TAREFA 5$)+$ TAREFA $6=20+6=26$ dias

Tarefa $7: 5+14=19$ dias

Tarefa 8: $5+26=31$ dias

Tarefa 9: $\max ($ TAREFA 7 , TAREFA 8$)+$ TAREFA $9=31+5=36$ dias

Desta forma a duração na construção será de 36 dias.

- Para a empresa "CULTURA SEM LIMITES" temos:

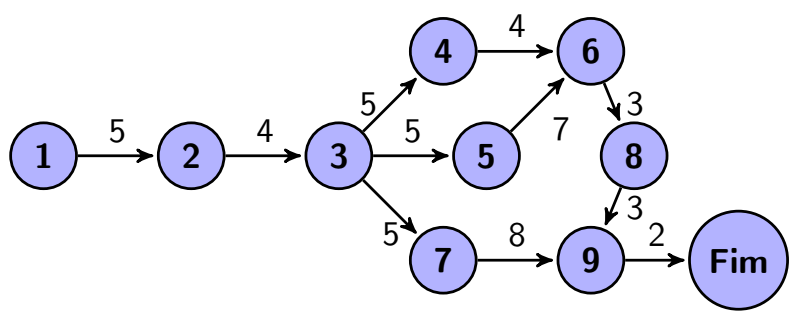

Figura 2.8: Grafo empresa "CULTURA SEM LIMITES"

Tarefa 1: 5 dias

Tarefa 2: $4+5=9$ dias

Tarefa $3: 5+9=14$ dias

Tarefa $4: 4+14=18$ dias

Tarefa $5: 7+14=21$ dias

Tarefa $6: \max ($ TAREFA 4 , TAREFA 5$)+$ TAREFA $6=21+3=24$ dias

Tarefa $7: 8+14=22$ dias

Tarefa 8: $3+24=27$ dias

Tarefa 9: $\max ($ TAREFA 7 , TAREFA 8$)+$ TAREFA $9=27+2=29$ dias

Desta forma a duração na construção será de 29 dias. 
Desta maneira os alunos poderão concluir que a empresa "CULTURA SEM LIMITES" será vencedora da licitação para a construção.

(b) Análise do tempo de atraso.

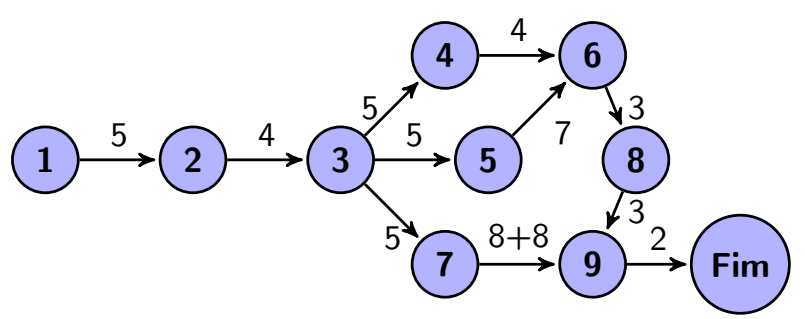

Figura 2.9: Grafo empresa "CULTURA SEM LIMITES" com atraso

Tarefa 1: 5 dias

Tarefa $2: 4+5=9$ dias

Tarefa $3: 5+9=14$ dias

Tarefa $4: 4+14=18$ dias

Tarefa $5: 7+14=21$ dias

Tarefa 6: $\max ($ TAREFA 4 , TAREFA 5$)+$ TAREFA $6=21+3=24$ dias

Tarefa $7: 8+14+(8$ dias de atraso $)=30$ dias

Tarefa $8: 3+24=27$ dias

Tarefa 9: $\max ($ TAREFA 7 , TAREFA 8$)+$ TAREFA $9=30+2=32$ dias

Desta forma a nova duração na construção será de 32 dias e assim verifica-se 3 dias de atraso em relação ao prazo final.

\section{Resultados}

Nesta seção vamos descrever alguns pontos observados na realização das atividades. Atentos aos alunos, informamos que as salas de aulas são formadas de forma bem heterogênea, não existindo assim uma diferenciação de alunos, desta forma ambas as salas contam com alunos empenhados como também alunos com rendimento insatisfatório, bem como alunos desmotivados e indisciplinados. Portanto, faremos as observações separadamente apenas pelo critério das classes serem séries distintas.

\subsection{Atividade 1}

1. Primeiro item

A primeira atividade consistia em um exercício extraido do banco de questões [7] da Olímpiada Brasileira de Matemática das Escolas Públicas OBMEP 2014, onde os alunos deveriam apenas encontrar um ciclo hamiltoniano para o problema.

(a) Observando a oitava série: 
- 10 duplas conseguiram atingir o objetivo esperado, sendo que alguns alunos questionavam a facilidade da questão.

- 2 duplas não compreenderam o fato de que a personagem em questão deveria retornar ao ponto de partida, sendo assim deixaram de realizar a atividade completamente.

- 1 dupla marcou todos os caminhos, e assim errou o item.

- 1 dupla não realizou as atividades.

(b) Terceira série:

- 13 duplas realizaram a tarefa corretamente. Utilizando até mesmo as iniciais dos nomes das cidades fictícias para indicar o caminho proposto.

- 2 duplas não observaram atentamente o enunciado, e não retornaram ao vértice inicial.

- 1 dupla simplesmente não realizou a atividade, por falta de interesse e compromisso com a educação.

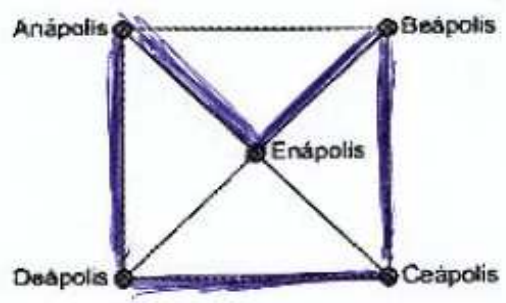

Figura 2.10: Resposta parcialmente correta do exercício 1 item $a$ para oitava série

2. Segundo item

Assim como o item "a" do problema, este item também consiste em localizar um ciclo hamiltoniano, agora faltando uma das arestas.

(a) Oitava série:

- 10 duplas compreenderam bem o problema e realizaram de maneira satisfatória.

- 2 duplas não conseguiram compreender a situação e não retornaram ao vértice inicial. As mesmas duplas que erraram a atividade anterior.

- 2 duplas não conseguiram pensar em um novo caminho, pois a aresta retirada fazia parte da solução encontrada anteriormente.

(b) Terceira série:

- 12 duplas realizaram de maneira satisfatória a atividade. 
- 3 duplas novamente não observaram o fato de ter que retornar ao vértice inicial.

- 1 dupla novamente não realizou a atividade.

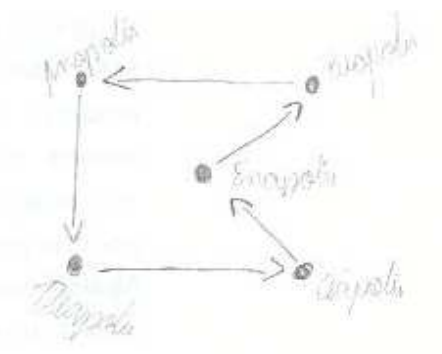

Figura 2.11: Resposta correta item B

\section{Terceiro Item}

Diferente dos dois ítens anteriores, este item exigia que o aluno mostrasse não ser possível realizar o ciclo hamiltoniano com a inserção de quatro novos vértices.

(a) Oitava série:

- 11 duplas tentaram mais de cinco caminhos diferentes, e verificaram que nenhum dos caminhos tentados, satisfaziam os objetivos propostos.

- 3 duplas tentaram uma ou duas vezes, porém não concluindo que não era possível.

(b) Terceira série:

- 13 duplas tentaram mais de cinco caminhos diferentes, e verificaram que nenhum dos caminhos tentados, satisfaziam os objetivos propostos.

- 1 dupla tentou 3 vezes, porém não concluiu a questão.

- 2 duplas não tentaram ao menos uma vez.

Esperava-se que alguma dupla, principalmente da terceira série do ensino médio, pudesse tentar alguma maneira lógica de mostrar, e não pelo método das possibilidades.

\subsection{Atividade 2}

Como segunda atividade foi proposto um exercício sobre a construção de casas de madeira para exposições nas cidades sedes da copa do mundo. A atividade foi dividida em dois ítens para a melhor compreensão dos alunos.

\section{Primeiro Item}

Como primeiro item, eram apresentadas duas tabelas para o processo de licitação da construção das casas e cabia aos alunos à determinação da empresa que construiria em menor tempo. Vamos aos resultados. 


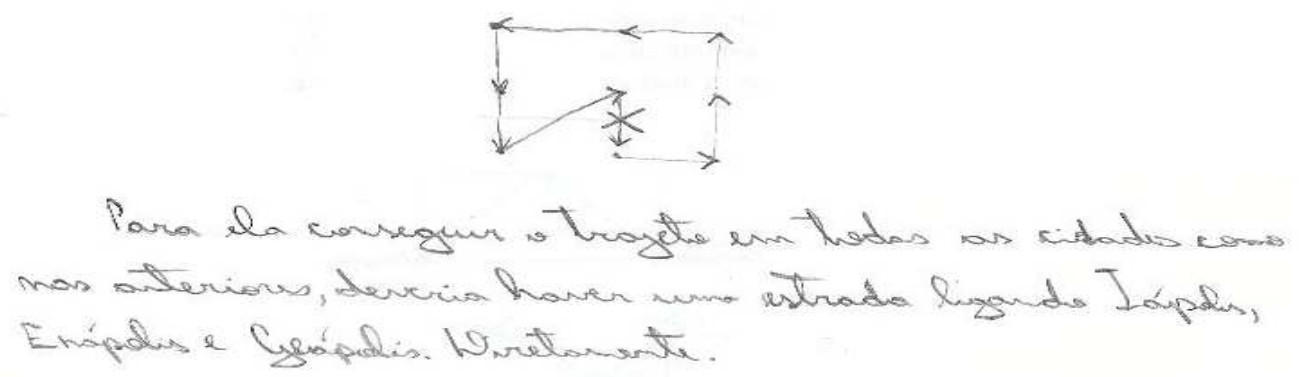

Figura 2.12: Resposta Parcialmente correta item C

(a) Oitava série

- 8 duplas não conseguiram compreender o que estava sendo pedido no exercício e por isso não realizaram as atividades. Resultado até que esperado pelo nível de complexidade do exercício.

- 5 duplas se esforçaram para chegar a uma solução, porém apenas realizaram as somas das durações de maneira incorreta, pois não compreenderam o fato de que algumas atividades distintas poderiam serem feitas simultaneamente, sendo assim, somaram a duração das tarefas. Obtendo respectivamente 45 e 41 dias.

- 1 dupla percebeu o fato de que mais de uma atividade poderiam ser realizadas simultaneamente, porém não conseguiu chegar no resultado esperado.

(b) Terceira série

- 5 duplas não se atentaram as condições iniciais do problema, sobre o fato de que algumas tarefas poderiam ser realizadas simultaneamente e com isso acelerando o tempo de construção. Desta forma somaram os valores de todos os dias de processo. Obtendo assim 45 dias para a primeira empresa e 41 para a segunda, desta forma sagrando-se vencedora a segunda empresa.

- 4 duplas entenderam que tarefas poderiam ser feitas simultaneamente, porém não conseguiram associar quais tarefas poderiam ser realizadas concomitantemente, somando assim os números dos dias que não tinham as mesmas tarefas como pré-requisitos. Obtendo assim valores errados. 
- 2 duplas realizaram a construção de uma idéia básica de grafo, conseguindo assim formar uma representação que melhor as ajudassem a solucionar tal problema, porém se confundiram na soma da duração dos dias.

- 1 dupla realizou todo o processo de construção do grafo corretamente e chegou a somar e chegou a encontrar a resposta correta do item, porém não foi mencionada.

- 4 duplas não se esforçaram para nem ao menos tentar solucionar o problema e questionaram a diferença no nível de dificuldade da atividade anterior.

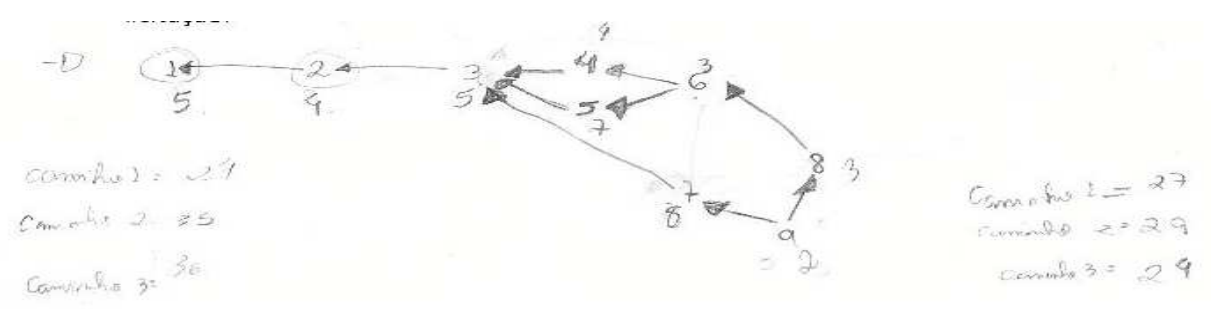

Figura 2.13: Resposta parcialmente correta exercicio 2 item a

2. Segundo Item

Uma vez conhecida a empresa vencedora, as obras são iniciadas, mas alguns imprevistos ocorreram devido a uma greve de funcionários, o que atrasou a entrega de uma determinada tarefa em oito dias. Acarretando um possível atraso na entrega final. Dever do aluno seria verificar se houve ou não atraso.

(a) Oitava série

- 2 duplas argumentaram que como o tempo de paralização foi de 8 dias o possível atraso seria de 8 dias por não terem compreendido o contexto do exercício.

- 5 duplas adicionaram apenas os 8 dias de paralização na quantidade de dias anterior, desta maneira obtemos $41+8=49$ dias.

- 6 duplas não realizaram a atividade por não terem realizado a atividade anterior.

(b) Terceira série 
- 4 duplas não realizaram a atividade tendo em vista que não realizaram o item anterior.

- 8 duplas desenvolveram estratégias paralelas como somar a duração dos dias e descontar os períodos simultâneos, porém, ao término, adicionaram o tempo de atraso.

- 3 duplas chegaram a esboçar a representação em formato de um grafo, porém errando nos cálculos dos procedimentos.

- 1 dupla atingiu o objetivo esperado chegando a solução esperada e em seguida observaram que o tempo que o funcionário de colocação das portas e batentes permaneceu parado não deveria ser adicionado ao tempo total, tendo em vista que outros procedimentos ainda não haviam sido realizados e desta forma constatou um tempo adicional de 3 dias.

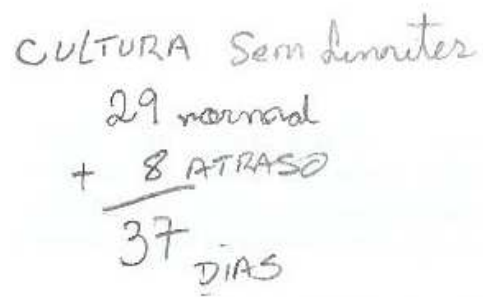

Figura 2.14: Resposta incorreta exercício 2 item b

\section{Resumo dos Resultados}

Observe abaixo os resultados individuais de cada turma.

\subsection{Oitava série do ensino fundamental}

\begin{tabular}{|l|l|l|l|}
\hline Exercício 1 & Satisfatório & Parcialmente & Insatisfatório \\
\hline item $a$ & 10 & 2 & 2 \\
\hline item $b$ & 10 & 2 & 2 \\
\hline item $c$ & 0 & 11 & 3 \\
\hline
\end{tabular}

Tabela 2.1: Tabela 1: Resultados exercício 1, oitava série 


\begin{tabular}{|l|l|l|l|}
\hline Exercício 2 & Satisfatório & Parcialmente & Insatisfatório \\
\hline item $a$ & 0 & 6 & 8 \\
\hline item $b$ & 0 & 5 & 9 \\
\hline
\end{tabular}

Tabela 2.2: Tabela 2: Resultados exercício 2, oitava série

\subsection{Terceira série do ensino médio}

\begin{tabular}{|l|l|l|l|}
\hline Exercício 1 & Satisfatório & Parcialmente & Insatisfatório \\
\hline item $a$ & 13 & 2 & 1 \\
\hline item $b$ & 12 & 3 & 1 \\
\hline item $c$ & 0 & 14 & 2 \\
\hline
\end{tabular}

Tabela 2.3: Tabela 1: Resultados exercício 1, terceira série

\begin{tabular}{|l|l|l|l|}
\hline Exercício 2 & Satisfatório & Parcialmente & Insatisfatório \\
\hline item $a$ & 3 & 4 & 11 \\
\hline item $b$ & 1 & 11 & 4 \\
\hline
\end{tabular}

Tabela 2.4: Tabela 2: Resultados exercício 2, terceira série

Estes são os resultados alcançados pelas turmas. Após a análise dos resultados, os exercćios foram refeitos juntamente com as respectivas turmas e esclarecendo as dúvidas dos alunos.

\section{Considerações Finais}

Nesta seção faremos alguns relatos com sugestões de alterações no desenvolvimento das atividades relatadas na seção anterior, para que os alunos possam apresentar um melhor desempenho, e assim atingindo a totalidade dos objetivos.

\subsection{Modificações}

A principal modificação para uma melhor realização de todos os exercícios é a definição de um lugar específico para a resolução dos alunos, além de orientações sobre que não serão aceitos cálculos e raciocínios fora da região delimitada.

No segundo exercício também se faz necessário uma modificação no texto presente do item $b$ sobre o atraso na construção da obra. A folha de atividade aplicada para os alunos trazia a seguinte pergunta: 
"Considerando que a empresa vencedora teve um problema com o funcionário responsável pela colocação dos batentes das portas e janelas, e que este se manteve em greve por oito dias, somente quando sua situação foi regularizada este voltou ao serviço, determine quantos dias a obra foi atrasada."

A pergunta formulada desta maneira, induz o aluno afirmar que houve um atraso. Portanto é necessário adicionar ao final da frase um complemento, ficando da seguinte forma:

"Considerando que a empresa vencedora teve um problema com o funcionário responsável pela colocação dos batentes das portas e janelas, e que este se manteve em greve por oito dias, somente quando sua situação foi regularizada este voltou ao serviço, determine, caso ocorra, de quantos dias será o atraso da obra?"

Uma outra modificação necessária é uma acerto em alguns pré-requisitos dos procedimentos para a construção das casas de madeira.

\begin{tabular}{|l|c|c|}
\hline Tarefas & Pré-requisitos & Dias \\
\hline 1. Limpeza do terreno & Nenhum & 4 \\
\hline 2. Produção e colocação da fundação & 1 & 3 \\
\hline 3. Produção da estrutura & 2 & 7 \\
\hline 4. Colocação das tábuas externas & 3 & 4 \\
\hline 5. Colocação do telhado & 3 & 6 \\
\hline 6 Instalação do encanamento e fiação & 4 e 5 & 6 \\
\hline 7. Colocação dos batentes de janelas e portas & 3 & 5 \\
\hline 8. Instalação das Janelas e portas & 6 & 5 \\
\hline 9. Pintura interior & 7 e 8 & 5 \\
\hline
\end{tabular}

Tabela 2.5: Tabela original atividade 2

As modificações das tabelas são necessárias uma vez que para a instalação das janelas e portas é necessário que a colocação dos batentes de portas e janelas esteja concluído e não a instalação dos encanamentos e fiações, conforme citado na tabela anterior.

Por fim, observamos que faltou realizar a devolutiva aos alunos das atividades corrigidas, visando uma melhor aprendizagem dos conceitos.

\subsection{Conclusões finais}

A teoria dos grafos apresenta aspectos que merecem destaque no currículo da educação básica brasileira, pois é capaz de contribuir para a formação do indivíduo autônomo, criativo e capaz de aprender a aprender. 


\begin{tabular}{|l|c|c|}
\hline Tarefas & Pré-requisitos & Dias \\
\hline 1. Limpeza do terreno & Nenhum & 4 \\
\hline 2. Produção e colocação da fundação & 1 & 3 \\
\hline 3. Produção e colocação da estrutura & 2 & 7 \\
\hline 4. Colocação das tábuas externas & 3 & 4 \\
\hline 5. Colocação do telhado & 3 & 6 \\
\hline 6 Instalação do encanamento e fiação & 4 e 5 & 6 \\
\hline 7. Colocação dos batentes de janelas e portas & 3 & 5 \\
\hline 8. Instalação das janelas e portas & 7 & 5 \\
\hline 9. Pintura interior & 7 e 8 & 5 \\
\hline
\end{tabular}

Tabela 2.6: Tabela modificada atividade 2

Documentos oficiais do Ministério da Educação apresentam a resoluções de problemas como uma alternativa para inserir o aluno em um mundo contemporâneo, visto que as escolas de educação básica devem abordar temas pertinentes que possam contribuir com desenvolvimento do cidadão que se deseja formar.

Em nossa dissertação de mestrado apresentamos conceitos básicos e históricos sobre teoria dos grafos para que este trabalho possa a vir ser aplicado com a educação básica. Especificamente para este trabalho foram elaboradas duas atividades extras curriculares, a primeira de baixa dificuldade e segunda em um nível mais avançado. Para que obtivéssemos resultados mais amplos, as atividades foram aplicadas em duas séries ou anos distintos, sendo uma oitava série e um terceiro ano, respectivamente séries finais dos seus ciclos, ensino fundamental II e ensino médio, ambas em uma escola estadual. Apesar da habitual desmotivação por parte de alguns alunos com o sistema educacional, conseguimos encontrar grupos de alunos alunos que se propuseram a desenvolver as atividades extras curriculares.

De um modo geral, os resultados foram satisfatórios, e me rendeu um avanço em minha prática docente, pretendo continuar abordando atividades relacionadas a grafos em todas as salas a qual vier lecionar futuramente.

Na seção abaixo encontram algumas sugestões de atividades que podem ser trabalhadas com alunos de educação básica, cabendo ao professor responsável selecionar e adaptar ao nível de seus alunos.

\subsection{Sugestões de Atividades}

Abaixo estão listados diversos problemas que podem ser abordados pela teoria dos grafos em diferentes momentos para diversas salas do ensino básico.

1. Na cidade de Épsilon existem 45 casas cada uma com uma única linha de telefone, considerando que as linhas são conectadas. Responda: 
(a) É possível conectar estas linhas telefônicas de modo que cada uma seja ligada a exatamente outros 7 telefones?

(b) E se for conectados a exatamente 6 outras linhas telefônicas?

2. Os amigos João, Pedro, Antônio, Marcelo e Francisco sempre se encontram para conversar e as vezes jogar dama, xadrez e dominó. As preferências de cada um são as seguintes:

- João só joga Xadrez,

- Pedro não joga dominó,

- Antônio joga tudo,

- Marcelo não joga xadrez e dominó,

- Francisco não joga nada.

(a) Represente através de um grafo $G=(V, A)$ todas as possibilidades de um amigo jogar com os demais. Defina $V$ e $A$.

(b) Defina um subgrafo em que todos, menos Francisco, joguem ao mesmo tempo.

3. Em um reino existem 101 cidades, algumas delas são conectadas por estradas, e cada par de cidades é conectado por um e somente um caminho simples. Quantas estradas existem?

4. Um tabuleiro de xadrez tem a forma de uma cruz, obtida apagando-se os quadrados do canto de um tabuleiro $4 x 4$. É possível que um cavalo faça um passeio neste tabuleiro, passando por todas as casas exatamente uma vez, e terminando na mesma casa que começou?

5. Maria convidou nove garotos e nove garotas para a sua festa de aniversário. Ela preparou camisetas com os números de 1 a 18, ficou com a de número 1 e distribuiu as demais para seus convidados. Durante uma dança, ela observou que a soma dos números de cada casal era um quadrado perfeito. Quais pares estavam dançando?

6. Existem 30 cidades em um país. Cada uma delas conectadas a cada uma das outras por uma estrada. Qual é o número máximo de estrada que podem ser fechadas de modo que ainda seja possível viajar de uma cidade á qualquer outra? 



\section{Referências Bibliográficas}

[1] ALVES, R. S. O. Um caminho para combater a dengue. Disponível em: < http://m3.ime.unicamp.br/recursos/1060>. Acesso em: 22 ago. 2013.

[2] COSTA, P. Teoria de Grafos e suas Aplicações. 2011. 77 f. Dissertação (Mestrado Profissional em Matemática) - Instituto de Geociência e Ciência Exatas, Universidade Estadual Paulista "Julio de Mesquita Filho", Rio Claro, 2011.

[3] FOMIN, D.; GENKIN, S.; ITENBERG, I. Círculos matemáticos: a experiência russa. Rio de Janeiro: IMPA, 2012.

[4] História e imagens do Icosain Game. Disponível em: < http://www.ime.usp.br/ yw/2013/grafinhos/aulas/cap4.pdf >. Acesso em 22 jul. 2014.

[5] Instituto Brasileiro de Geografia e Estatística: Avaí SP. Disponível em: < http://cod.ibge.gov.br/23AT2 >. Acesso em: 22 ago. 2014.

[6] JURKIEWICZ, S. Grafos: uma introdução. Apostila 5 do Programa de Iniciação Científica Jr. (PIC), 2009. Disponível em: < http://www.obmep.org.br/prog_ic_2010/apostila2010.html>. Acesso em: 20 ago. 2013.

[7] OBMEP 2014: banco de questões. Disponível em: < http://www.obmep.org.br/banco.htm>. Acesso em: 03 maio 2014.

[8] MALTA, G. H. S. Grafos no Ensino Médio: uma inserção possível. 2008. 138 f. Dissertação (Mestrado em Ensino de Matemática) - Instituto de Matemática, Universidade Federal do Rio Grande do Sul, Porto Alegre, 2008.

[9] MENDES, D. As pontes de Königsberg. Disponível em: < http://m3.ime.unicamp.br/recursos/1258>. Acesso em: 22 ago. 2013. 
[10] Problemas e Exercícios sobre Grafos. Disponível em : < http://www.inf.ufsc.br/grafos/problemas/index.htm > . Acesso em 22 jul. 2014. 